\title{
Drying Drop Technology as a Possible Tool for Detection Leukemia and Tuberculosis in Cattle
}

\author{
Tatiana A. Yakhno ${ }^{*}$, Anatoly A. Sanin ${ }^{1}$, Robert G. Ilyazov², Gulusa V. Vildanova ${ }^{2}$, \\ Rafat A. Khamzin ${ }^{3}$, Nadezhda P. Astascheva4, Mikhail G. Markovsky5, \\ Vadim D. Bashirov ${ }^{6}$, Vladimir G. Yakhno ${ }^{1}$ \\ ${ }^{1}$ Department of Radiophysical Methods in Medicine, Institute of Applied Physics Russian Academy of Sciences \\ (IAP RAS), Nizhny Novgorod, Russia \\ ${ }^{2}$ Department of Agricultural Sciences, Academy of Sciences of the Republic of Tatarstan (AS RT), Kazan, Russia \\ ${ }^{3}$ Department of Biotechnology and Standardization, Bauman Kazan State Academy of Veterinary Medicine \\ (KSAVM), Kazan, Russia \\ ${ }^{4}$ Department of Technique and Technology, Financial Technological Academy (FTA), Moscow Region, Korolyev, \\ Russia \\ ${ }^{5}$ Department of Trial Wine-Making, North-Caucasian Zonal Research Institute of Horticulture and Viticulture of \\ the Russian Academy of Agricultural Sciences (NCZRIH \& V), Krasnodar, Russia \\ ${ }^{6}$ Department of Food Biotechnology, Orenburg State University (OSU), Orenburg, Russia \\ Email: ‘yakhta13@gmail.com
}

Received 24 December 2014; accepted 10 January 2015; published 16 January 2015

Copyright (C) 2015 by authors and Scientific Research Publishing Inc.

This work is licensed under the Creative Commons Attribution International License (CC BY).

http://creativecommons.org/licenses/by/4.0/

c) (i) Open Access

\section{Abstract}

Usual response of organism to viral or bacterial invasion represents antibodies production, qualitative and quantitative changes in composition of biological fluids. These changes influence conformation and surface characteristics of macromolecules (proteins), which become apparent in sessile drying drops, when they form aggregates due to salting-out effect and sediment. The bottom adsorption layers change their adhesive and viscoelastic properties in time depending on fluid composition and structure. The aim of this study was verification the idea of using this phenomenon in rapid vet diagnostics. Milk, blood and serum samples of 183 cows were tested using Drop Drying Technology (DDT). A drop of tested fluid dried on a polished quartz plate, oscillated with constant frequency-60 kHz. Mechanical properties of the drop changed during drying, influenced the electrical conductivity of the quartz plate. This signal was converted to the AcousticalMechanical Impedance (AMI) and displayed as a curve in coordinates AMI vs. Time. Shape of the AMI curve reflected this dynamics, and was used as a target for quantitative comparison between

"Corresponding author. 
control and infected animals. Frequency analysis of the estimated parameters of the curves was performed using features of the Excel program. Powerful method of artificial neural network processing of the experimental data was also tested in this work as a possible tool for future development. Significant differences between control, Bovine leucosis virus positive (BLV+) and Bovine tuberculin positive (BTub+) cattle groups were obtained using all biological fluids-blood, serum and milk. We fixed also a season shift of the data, but distinction between groups still remained. In serum and milk some features of the AMI curves were more stable, and retained diagnostic properties when combined winter and spring databases. Further development of DDT is proposed.

\title{
Keywords
}

\author{
Sessile Drying Drops, Biological Fluids, Dynamics of Mechanical Properties, Acoustical \\ Impedancemetry, Vet Diagnostics
}

\section{Introduction}

Drying drop phenomenon has been actively studied all over the world the last 25 years [1]. Thanks to the many possible useful applications, representatives of different professions-from physicists, materials scientists and engineers to forecasters, biologists and doctors-are interested in this research. Last decade medical researchers Savina [2], Shabalin \& Shatokhina [3], and Rapis [4] had shown experimentally that microscopic structures in dried drops of biological fluids in healthy and ill patients were differing. The same time sessile desiccated drop, as a natural model for studying dynamics of self-organizing processes, actively used in physical experiments. Deegan [5], Deegan et al. [6] were the first who gave a physical explanation and mathematical description of the drying drop phenomenon. Summarizing the results of research, it can be argued that dynamical processes in the drops at the same environments and drop volume are governed by a set of factors: liquid composition and structure (dispersity) [6] [7], wetting ability [8]-[10], liquid/substrate thermal conductivities ratio [11], substrate roughness [12] [13], as well as initial level of $\mathrm{pH}$ and salinity [14]. These factors influence such characteristics as a drop shape [15], surface thermocapillary (Marangony) flows [16]-[18], redistribution of the chemicals in accordance with their surface and diffusive properties [19]-[21], total evaporation intensity, and diffusion capacity [22]. Thus, if we standardize the environmental conditions, drop volume and substrate, all processes in the drying drops will be defined solely by liquid content and structure. As a result of a lot of identical interrelated events, a unique dried drop image arises [23] [24]. Nevertheless the simplicity, dried drop microscopy of biological fluids did not have a broad distribution in rapid medical diagnostics due to some inconveniences: first, drops of volume of $10-20 \mathrm{ml}$ were used became ready for microscopic analysis only after 2 - 5 days of drying process (film water evaporation time from gel and texture formation); second, lack of strong formalize description of diagnostic morphological structures, which led to subjective inconsistent estimation; third, using of semiquantitative methods of accounting of results. Kim et al. [25] accelerated the processes using small-size drops $(100 \mathrm{nl})$ and 24-hours drying of the drops on glass plates in desiccators with hygroscopic powders, as well as development the computer-based classification and clustering of stains using pattern recognition algorithms. This technique allowed the authors to recognize images of stains via inverted microscope as signatures of fluid composition and substrate chemistry, for rapid biological testing. Two datasets of stain images were produced and made available online, one with consumable fluids, and the other with different buffer solutions ("biological fluids"). Brutin et al. [26] had demonstrated that cells—contained fluid (whole blood) also can be used in dried drop method: totally different patterns were formed according to whether the person was healthy or suffer from anaemia or hyperlipidaemia. Killeen et al. [27] proposed a new technology named Droplet Micro Chromatography (DMC) for rapid medical diagnostics. It was based on blood serum stain image progress during desiccation. Shortly, it consisted of registration the dynamics of optical image of small fields of desiccated droplet's surface through special window along droplet's radius with sequential video-signal processing and applying the Support Vector Machine classifier. The authors got dynamical signatures of desiccated droplets, and demonstrated good separation of the drying droplet patterns for myeloma and normal serum samples (Figure 1). Our 


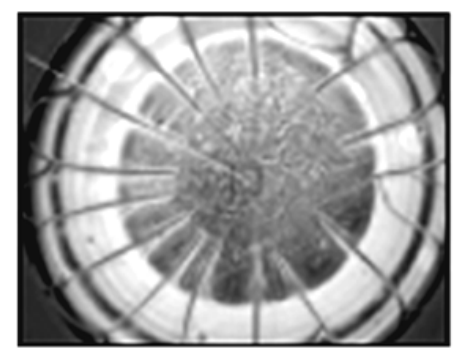

(a)

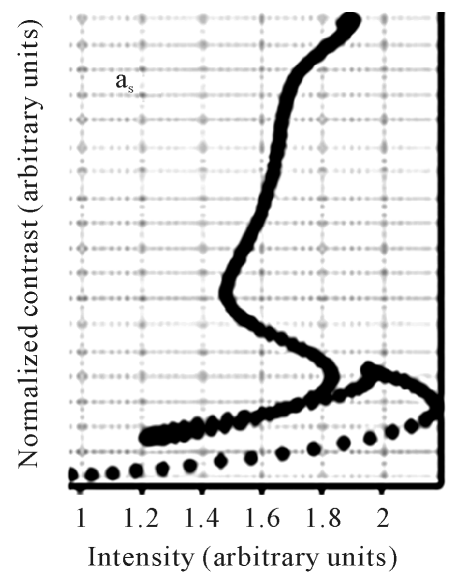

(c)

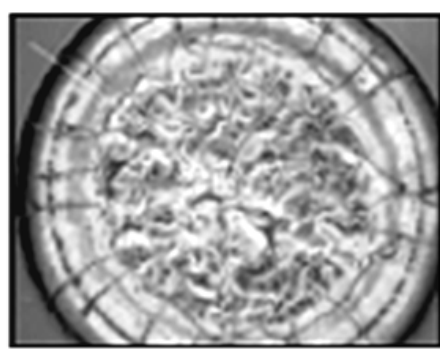

(b)

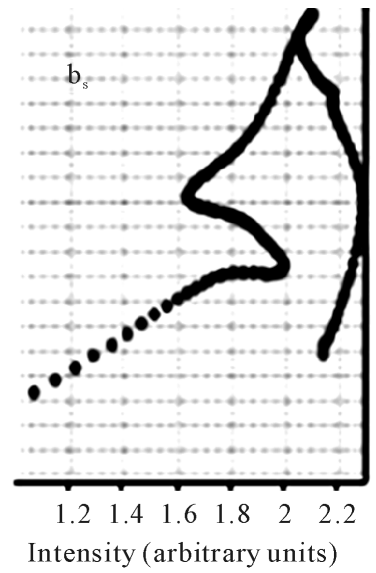

(d)

Figure 1. Images of the dried serum droplets from (a) a healthy individual; and (b) a patient with myeloma; (c) and (d) show the "signatures" of (a) and (b), respectively. This "signature" is created by plotting the changes of one parameter (intensity) against respective change in a different parameter (contrast), thus greatly reducing the noise caused by variations of droplet size and desiccation rate (from [27]. Reprinted with permission from Copyright Clearance Certer).

team reported the first results of getting "dynamical signatures" of complex fluids, using bottom-up processes in their desiccated drops [28]. Even if the phenomena involved in adsorption dynamics occur at molecular scale, they always correspond to a transient of the interfacial tension that can be monitored at macroscopic scale [29] [30]. Quartz Crystal Microbalance (QCM) has gained exceptional importance in the fields of (bio)sensors, material science, environmental monitoring, and electrochemistry based on the phenomenal development in QCMbased sensing during the last two decades [31]. The mainstream of recent QCM-based techniques is production of special coating layers for quartz plate, which are able to adsorb specifically target chemicals, and evaluate them quantitatively by quartz frequency shift [32] [33]. This approach, for example, allows Lin et al. [34] albumin determination with detection limits of $60-150 \mathrm{ppm}$, and Yakovleva et al. [35] glycoproteins determinations from $50 \mu \mathrm{g} / \mathrm{mL}$ to $1 \mathrm{mg} / \mathrm{mL}$. It was possible also to determine toxic components, and a number of specific antibodies in biological fluids, if a quartz plate coating contained immobilized specific antigens [36] [37]. Preparing of such coatings is quite difficult, expensive and long-time procedure. Sometimes it is more reasonable using easy, rapid and cheap application of uncoated quartz plate, basing on drying-drop phenomenon—Drying Drop Technique (DDT). The most sensible point here is quartz surface treatment, because it determines hydrophilichydrophobic properties and therefore interaction of liquid drop with quartz surface [38]. As a factor for liquids characteristics and quantitative comparison, we used mostly dynamical sediment forming processes in their desiccated drops, which were detected and traced by acoustical impedancemetry. Different human proteins salt water mixes [39] and natural human biological fluids [28] [40] were tested. There was proofed experimentally that dynamics of Acoustical-Mechanical Impedance (AMI) of drying drop is the ID characteristics of a liquid [41]-[43]. Thus, we had hoped to be able to distinguish infected animals from healthy ones, keeping in mind increasing of antibodies production, qualitative and quantitative changes in composition of biological fluids. The 
idea of our approach is reflected at the sketch (Figures 2(a)-(f)). Initially sessile drop is a homogenous colloid liquid, and evaporation flow from the liquid-air surface quite steady (Figure 2(a)). At the beginning of drying process due to heat exchange between drop, support and air, thermocapillary flow arises, and carries out colloid particles to the triplicate border zone. Together protein/salt relation falls at the central part of the drop [21], and salting-out process develops. Thus, the first liquid-solid phase transition vector is directed from periphery to the center. At the same time, upper and bottom adsorption layers begin to form. Upper layer sometimes can limit total evaporation level and hereby take part in drop's kinetic processes too. But, in real biological fluids usually bottom layer is more intensive, and grows up sooner. Thus, the second liquid-solid vector in sessile drop is directed bottom-up (Figure 2(b)). If we impose a shear load to the drop's support, the bottom sediment will manifest its physical properties, such as mass, friction, adhesion level, viscoelastic features (Figure 2(c)). If a drop dries on a polished quartz sensor plate, which oscillates with constant frequency, it is possible to trace the dynamics of integral mechanical properties of a bottom sediment layer by acoustical impedancemetry.

In accordance with our technology, this dynamics is reproduced as a curve in coordinates AMI vs. Time. Its geometrical features can be parameterized by some special algorithms, and compared quantitatively with corresponding etalon (for example, "norm-pathology") (Figure 2(d)). The results of statistical comparison are represented on a plane of features in coordinates of selected algorithms-the Shape Indices (Figure 2(f)). Detailed description of the technology can be found in [39] [43] [44]. In this paper, we demonstrate and analyze the results of testing whole blood, serum and milk samples from control cattle, and those animals, which gave positive serum reaction for leucosis virus and tuberculosis bacteria carrying revealed by standard veterinary diagnostic procedures. Thus it was known in advance with a certain degree of probability, which animals were healthy and were infected. Bovine leukemia virus (BLV) is widespread all over the world. Usually laboratory
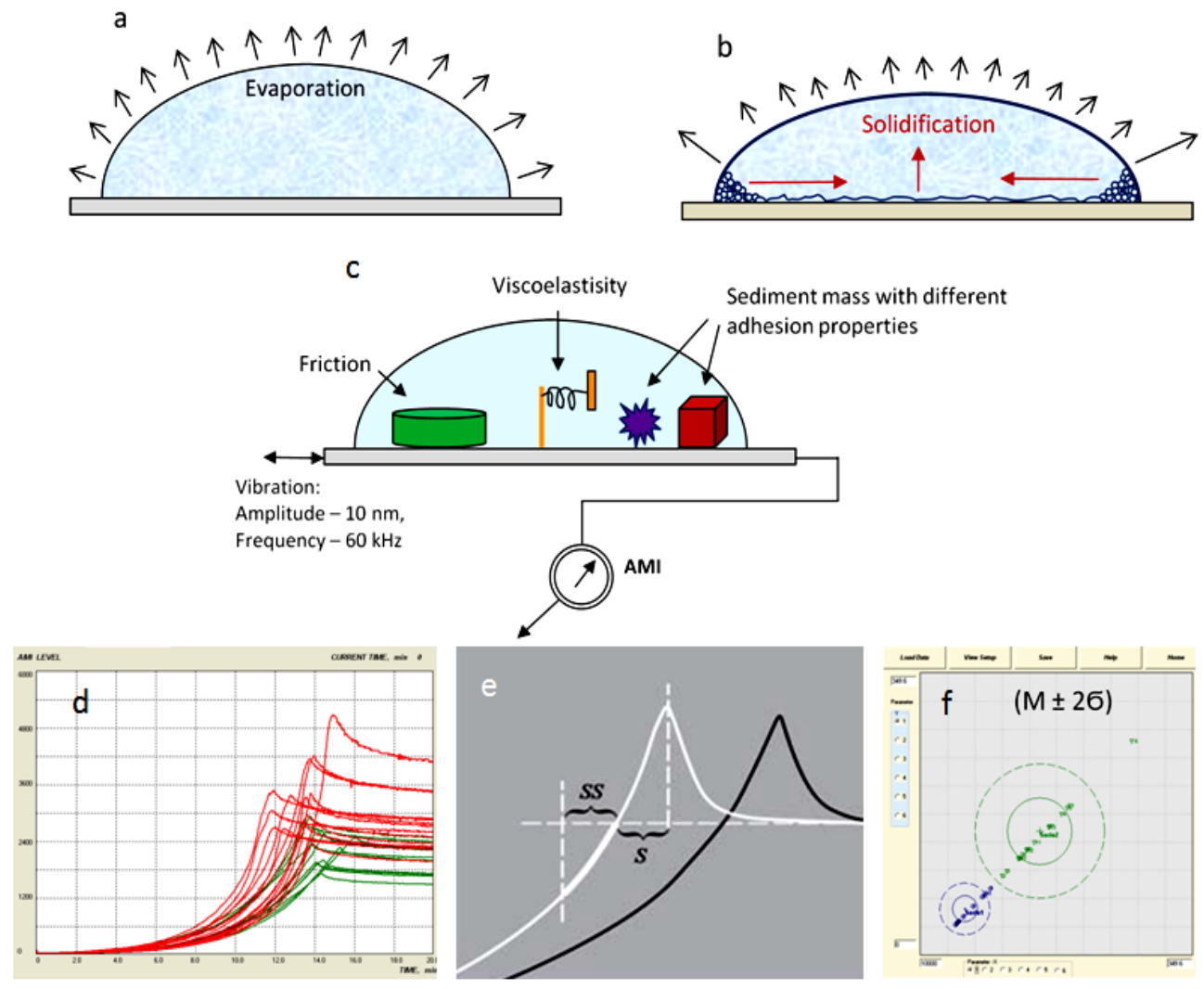

Figure 2. Scheme of extracting information on fluids status through bottom-up processes in their drying drops (see the text): (a) The initial state of a drop on a quartz plate; (b) Solid deposits begin to form; (c) Registering the dynamics of integral physical properties of sediments during drop drying by Acoustical Mechanical Impedance (AMI); (d) Presentation of untreated data (AMI vs. Time) on the interface; (e) Parameterization of the AMI curves by the Shape Index; and (f) Presentation of statistical differences between the groups under comparison. 
tests on blood, milk and tissues are required to confirm the disease. Most commonly, diagnosis is based on serology by looking for antibody to the virus in the blood of the animal. Bovine tuberculosis (BTub) is a contagious chronic disease of cattle caused by Mycobacterium bovis and associated with progressive emaciation and tubercle (granuloma) formation involving most usually the respiratory system but also other organs. As well as being of great economic importance to the livestock industry, because humans can be infected, it is also an important public health issue. Standard diagnostics requires 3 - 14 days, special chemicals and time-consuming procedures. DDT analysis takes $20 \mathrm{~min}$, and one drop of biological fluid of volume of $3 \mu \mathrm{l}$. Thus, it confirms a relevance of the study.

\section{Materials and Methods}

\subsection{Taking and Preparation of Biological Fluids}

Holstein dairy cattle, Black and White suit, 1 to 3 years old were used in the experiments. Blood, milk, and blood serum were sampling from 10 cattle herds in Tatarstan (Russia) from seropositive bovine leukemia virus $(\mathrm{BLV}+)$ animals, were detected as a result of routine veterinary examination using an agar gel immunodiffusion test (IDAG) [45]. The international standard method for detection of bovine tuberculosis (tuberculin test) was also used. It involved the intradermal injection of bovine tuberculin purified protein derivative (PPD) and the subsequent detection of swelling (delayed hypersensitivity) at the site of injection 72 hours later [46]. The cows, which gave seronegative reaction to BLV and BTub, were used as a control group. Blood was sampling from jugular vein with sterile needle and put into sterile tubes of volume of $10 \mathrm{ml}$. Serum was prepared from blood, which was preliminary heated in thermostat for $60 \mathrm{~min}$ at $+30^{\circ} \mathrm{C}-35^{\circ} \mathrm{C}$ for coagulation, and subsequent cooling in refrigerator at $+4^{\circ} \mathrm{C}$ for clot retraction. Serum was taken from the tubes by sterile pipette and put into $1.5 \mathrm{ml}$ eppendorfs. Milk samples were collected immediately after milking and mixing. All biological fluids were collected, pretreated, cooled $\left(4^{\circ} \mathrm{C}\right)$ and delivered by express ( 9 hours) in $1.5 \mathrm{ml}$ eppendorfs in a hermetically closed thermo-container from Kazan to Nizhny Novgorod. All fluids were preserved before shipping: milk-by $40 \%$ formaldehyde water solution (1 drop/100 mL), blood—by 10\% EDTA (ethylenediaminetetraacetic acid) water solution $(1 \mathrm{drop} / 1 \mathrm{ml})$, serum — by dried boric acid $(2 \mathrm{~g} / 1 \mathrm{ml})$. The samples were hold in refrigerator at $4{ }^{\circ} \mathrm{C}$, and heated to room temperature before testing. All laboratory procedures were carrying out with compliance the hygiene standards when working with infectious material (work rules and safety in veterinary laboratories). There were two series of experiments: one was in December 2013, and another one-in March 2014. Overall 183 samples of natural biological fluids were tested (Table 1).

\subsection{DDT Apparatus and Measuring Procedure}

Block diagram of the device is reproduced at Figure 3. A drop of a liquid (volume $3 \mu \mathrm{l}$ ) without any pretreatment dries on the polished end of the quartz plate. The quartz oscillates with constant frequency- $60 \mathrm{kHz}$, which equal resonance frequency of unload resonator. Oscillation amplitude is $\approx 10 \mathrm{~nm}$, velocity is $5 \mathrm{~mm} / \mathrm{sec}$ (for water), viscous wave penetration depth into liquid drop is about $10 \mu \mathrm{m}$, but, as soon as solidification begins, it increases progressively. Total electrical conductivity of the quartz plate loaded with drop is registered every 5 $\times 10^{-3} \mathrm{sec}$, herewith intrinsic conductivity of the unload resonator is taking away constantly by the bridge circuit. The final signal of electrical conductivity is converted to acoustical impedance, as (1):

Table 1. The number of animals used in the experiments.

\begin{tabular}{|c|c|c|c|c|c|c|c|}
\hline \multirow{3}{*}{$\begin{array}{l}\text { Biological } \\
\text { Fluids }\end{array}$} & \multicolumn{7}{|c|}{ Groups of Animals } \\
\hline & \multicolumn{2}{|c|}{$\mathrm{BLV}+$} & \multicolumn{2}{|c|}{$\mathrm{BTub}^{+}$} & \multicolumn{2}{|c|}{ Control } & \multirow{2}{*}{ Total } \\
\hline & December & March & December & March & December & March & \\
\hline Blood & 7 & 9 & 9 & 9 & 10 & 9 & 53 \\
\hline Serum & 4 & 8 & 10 & 8 & 18 & 10 & 58 \\
\hline Milk & 14 & 9 & 10 & 8 & 21 & 10 & 72 \\
\hline \multicolumn{8}{|c|}{ Overall: 183} \\
\hline
\end{tabular}






Figure 3. Block diagram of the method.

$$
|\mathrm{Z}| \sim 1 / \mathrm{I}
$$

where $|\mathrm{Z}|$ is the absolute value of the acoustical impedance of the drop in contact with resonator surface, I is a registered signal. Really, we squared this index, as $|Z|^{2}$, and got the transformed signal, named AMI, with more expressive shape of the curve for visual comparing.

Mirror polishing quartz plate surface was washed repeatedly by distilled water with cotton swab before and after every testing, blotted by absorbent paper, treated by alcohol wipes (70\% ethyl alcohol), and finally blotted by absorbent paper once more. We checked quartz plate clearance by special software, and examined its surface properties by water drop test. At the beginning of working day dried quartz surface was quite hydrophobic: a drop of distilled water $(3 \mu \mathrm{l})$, gently put on it by micropipette, had a liquid—solid contact aria $6.36 \pm 0.15 \mathrm{~mm}^{2}$. After the treatment described above it became $6.76 \pm 0.22 \mathrm{~mm}^{2}$, and repeated treatments did not influence this parameter considerably. Contact aria was determined by means of Levenhuk TopView Image Processing software (China). All testing procedures were carried out at $\mathrm{T}=20^{\circ} \mathrm{C}-22^{\circ} \mathrm{C}$ and $\mathrm{H}=63 \%-71 \%$ in a special closed room (box) with air cleaner and disinfection (bactericidal irradiator-recirculator Dozar-3, made in Russia).

Measuring module with quartz plate was placed at a special housing, which did not limit evaporation, but protected a drop against incidental air moving in the room. Before testing the samples were warmed up to room temperature, carefully agitated by overturning the tube no less than 10 times, and a drop of volume of $3 \mu \mathrm{l}$ was placed on the quartz plate end by micropipette (Biohit, Finland). Registration procedure was beginning in automatic mode just after drop placing. In this experiment, we tested only one drop of every sample. At the same time we put 6 - 8 drops of every sample of tested fluids (drop volume was $3 \mu l$ ) on new microscopic slides (ApexLab), treated preliminary by distilled water and alcohol, as well as it was described for a quartz plate. The drops were allowed to dry at room conditions 3 - 5 days before microscopic investigation (microscope digital camera Levenhuk C series). Drop desiccation process was also registered by video, and accelerated for viewing later by means of Movavi Video Editor (www.movavi.com).

\subsection{Software and Analytical Procedure}

AMI dynamics during drop drying was displayed at the screen in automatic mode, writing on-line and saving by means of special software. Every curve (some curves) from database (DB) could be displayed at the screen, as well as be represented as a number (numbers) on the plane of features in coordinates of special algorithms (Shape Indices). Description of some Shape Indices, were used here, can be find in Appendix A and Appendix B. Special software "Splitter" calculated arithmetic mean (M) and standard deviation (б) of selected AMI curves for every Shape Index, and represented them on the screen as $M \pm 26$. Calculated parameters for every curve were available also in special window at the interface. After measuring, Shape Indices were calculated for every group of animals, and numerical differences between groups for every Shape Index were represented by the software as $\mathrm{M} \pm 26$. We used also non-parametric Wilcoxon/Mann-Whitney Test (U) as distribution free method for checking up significance of differences between compared groups [47]. Frequency analysis of the estimated parameters of the algorithms was performed using features of the Excel program. Powerful method of artificial neural network processing of the experimental data was also tested in this work as a possible tool for future development. Procedure of disease identification was totally revised, allowing providing preliminary smoothing and normalization of data completely automatically. This data was used later for training of the complicating neural network until the acceptable level of health/disease category identification. This procedure was carried out with the program written in the Python language, designed in the Python $(\mathrm{x}, \mathrm{y})$ programming environment (https://code.google.com/p/pythonxy). Efficient feed-forward artificial neural network processing was based on the ffnet library (http://ffnet.sourceforge.net). 


\section{Result and Discussion}

\subsection{Blood}

Whole blood is the most complex polydisperse system, which represents blood cells (mostly, erythrocytes) dispersion in proteins colloidal water salt solution. Erythrocyte sedimentation rate (ESR) is usual laboratory test for health surveillance, although its physical—chemical mechanism is still unknown [48]. Every illness anyway influences the blood colloidal stability, and it can be detected by ESR growth. Thus, this index is nonspecific. Blood spots images depend on the packed cell volume (PCV), hemoglobin saturation and oxygenation, and serum composition. High reproducibility of blood drops images of different samples, dried on glass, is represented on Figure 4. We selected three blood samples of different groups under investigation, which drops dried on the glass looked very similar, and compared their AMI curves (Figure 5). It was found that they were not alike.

1
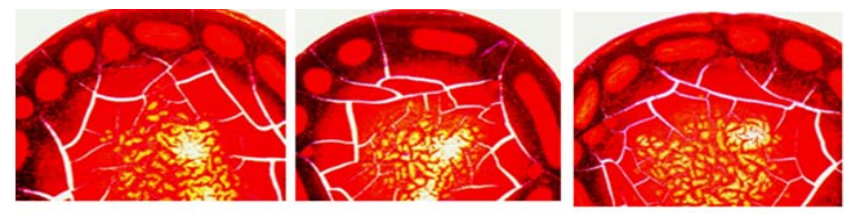

2
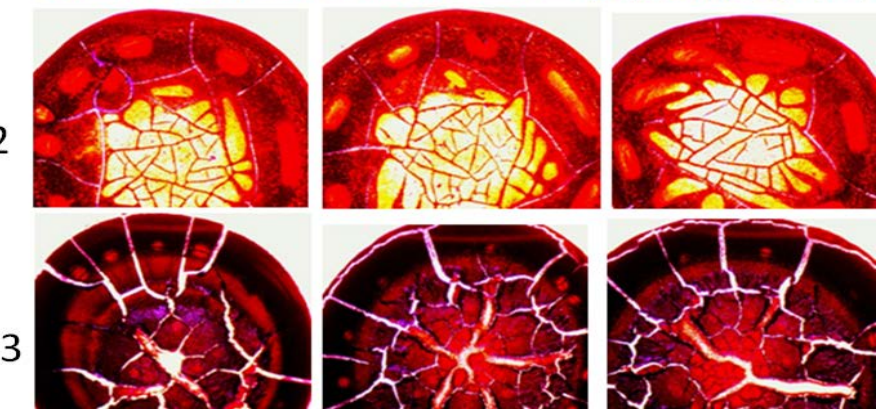

Figure 4. Reproducibility of dried blood drops images of different samples: 1-Control, 2-BLV+, 3-BTub+.
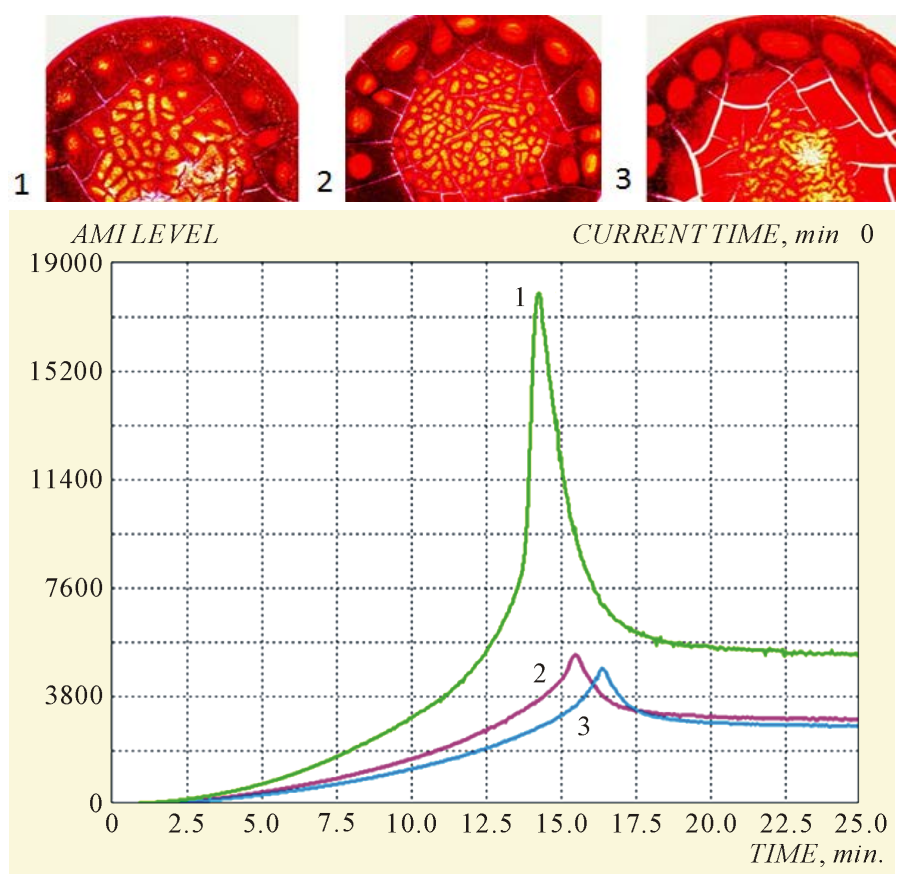

Figure 5. Dried blood drops images (top) and the AMI curves of the same samples (down): 1-Bovine BTub+, 2-BLV+, 3-Control. 
Thus, similarity in appearance did not mean binding dynamical similarity. Examples of blood drop drying processes in control, BLV+ and BTub+ samples are represented in video clips:

Control: https://www.dropbox.com/s/iu92xjuzbxxwhm3/Blood_Control.mp4?dl=0;

BLV+: https://www.dropbox.com/s/usf5x5p6cbpb406/Blood_BLV\%2B.mp4?dl=0;

BTub+: https://www.dropbox.com/s/5u1u0w7msffzfor/BLOOD_BTub\%2B.mp4?dl=0.

We chose BU_5 and BU_3 Shape Indices for the treatment of the AMI curves of blood samples, and built up joint histograms for the data frequency distribution analysis.

In spite of the fact that control and BLV+ animals in December and March had partially total frequency distribution area (Figure 6(a), Figure 6(b)), differences between these samples were highly significant $(\mathrm{P} \leq 0.01)$. We fixed also a season shift of the data (Figure 6(a), Figure 6(b)), whereby the united groups of controls and BLV+ animals of both December and March experiments didn't differ reliably (Figure 6(c), $\mathrm{P} \geq 0.05$ ). As for BTub+ group, it differed from control by the same BU_5 Shape Index (Figure 6(d)), and BTub+ group placed another area, than BLV+ group (Figure 6(b), Figure 6(d)), though differences between BTub+ and BLV+ using BU_5 Shape Index were insignificant $(P \geq 0.05)$. There was found that BTub+ and BLV+ animals can be divided by BU_3 Shape Index $(\mathrm{P} \leq 0.01)$. It recognized BTub+ animals, and disregarded BLV+ group from the control. Thus, using DDT for whole blood samples, we could differ with high significance sick animals from control ones, and split BTub+ (bacteria carriers) and BLV+ (virus carriers) animals.

\subsection{Serum}

Serum is the most commonly used media for medical and veterinary diagnostics, because it has quite constant reference rangers due to homeostasis; it is more suitable for biochemical analyzes and evaluation of special metabolites and antibodies-markers of this or that diseases. Reproducibility of images of serum drops, which dried on glass, was high for every sample, but they differed from sample to sample. The AMI curves of these samples had different shapes too (Figure 7). In December we've got highly significant differences between the control and BLV+ groups after the treatment of the AMI curves by BU_1 and BU_4 Shape Indexes $(P \leq 0.01)$. December's BTub+ group differed significantly from control by using BU_6 Shape Index (Figure 8(a)).

In March BS_1 Shape Index was the most informative (Figure 8(c), Figure 8(d)). It allowed good separation



Figure 6. The Shape Index BU_5 data frequency distribution of blood samples in control, BLV+ and BTub+ animals: (a) December experiment with BLV+; (b) March experiment with BLV+; (c) Unite (December + March) data; (d) March experiment with BTub+. 

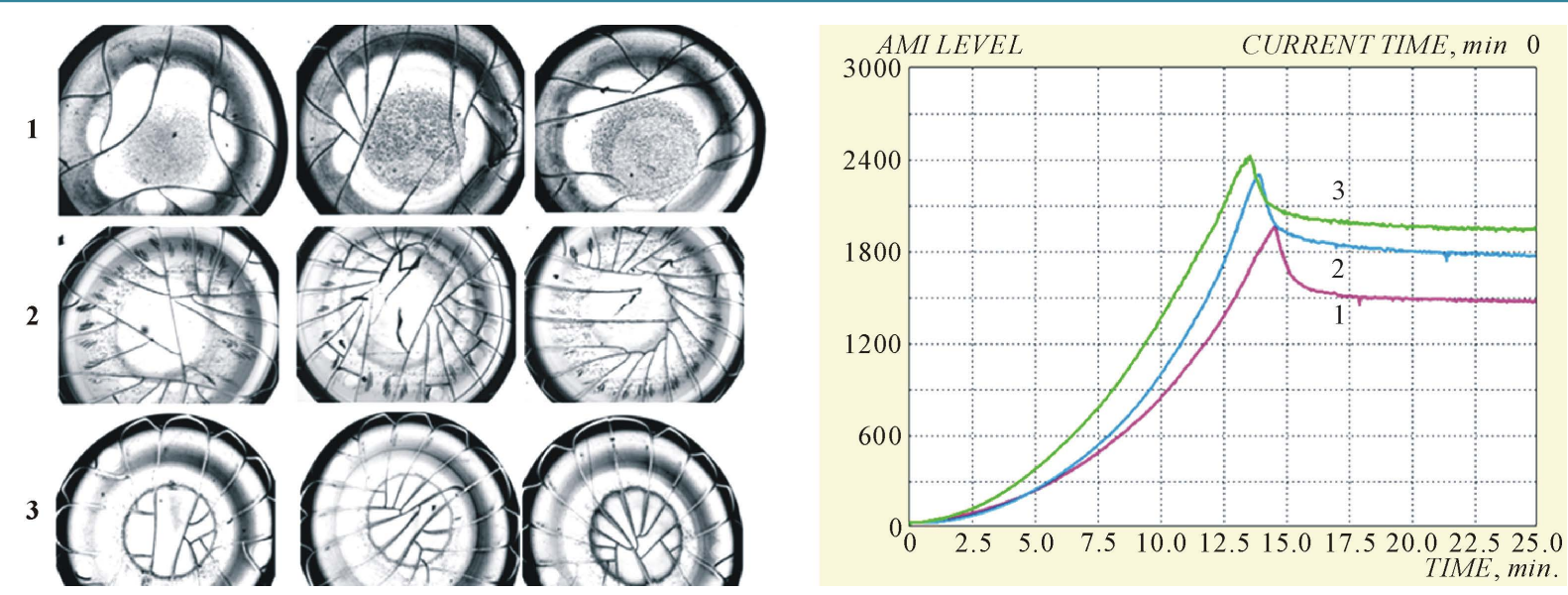

Figure 7. Dried serum drops images (left, three drops of each sample) and the AMI curves of the same samples (right): 1 Control, 2-BLV+, 3-BTub+.

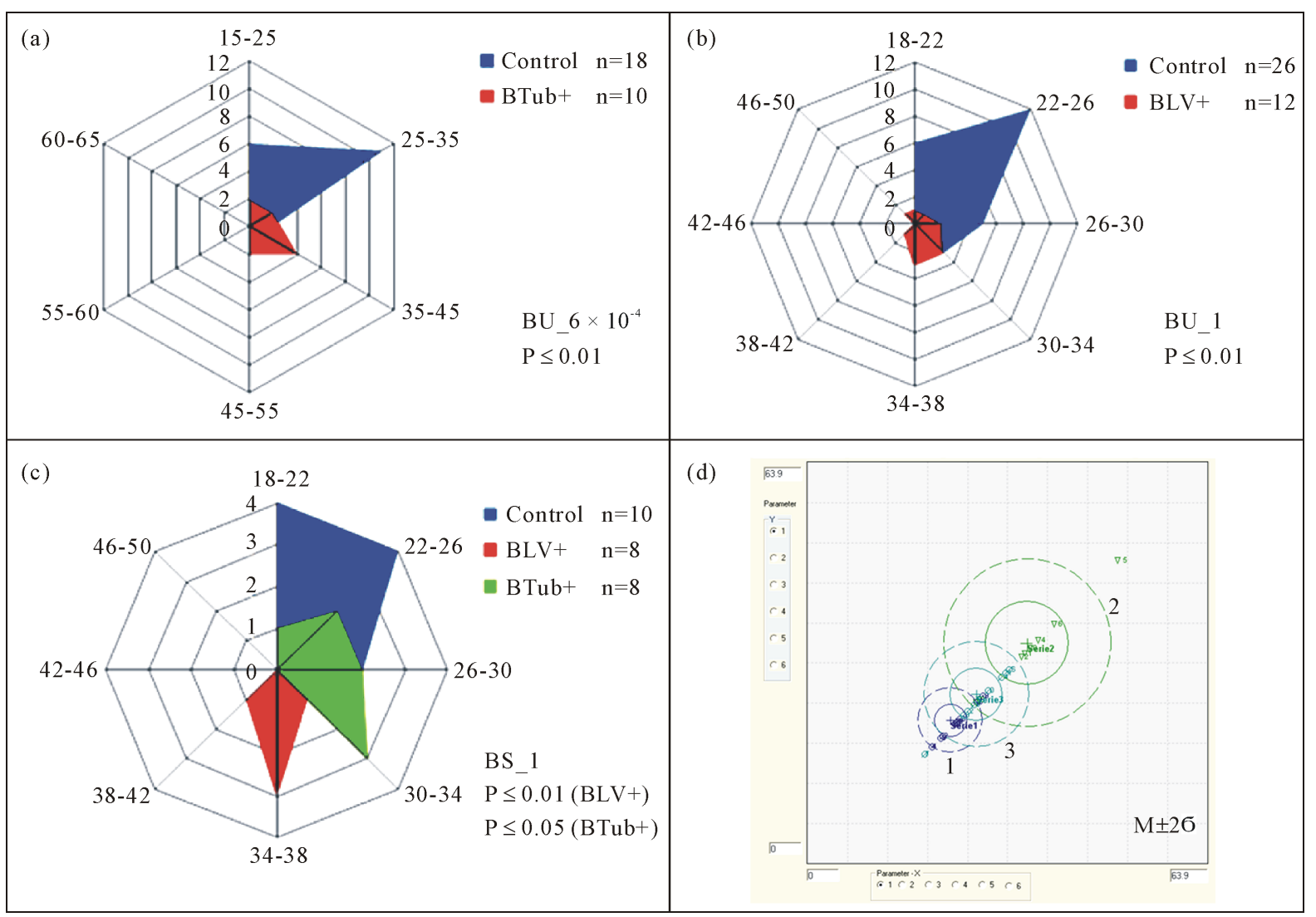

Figure 8. The Shape indices BU_6 (a) and BS_1 (b), (c) data distribution of serum samples in control, BTub+ and BLV+ animals; (c) united data (December + March) joint distribution in control and BLV+ animals; (d) representation of the data of March experiment on the plate of features in coordinates of the Shape Index BS_1 at the Splitter interface: 1 -Control $(\mathrm{M} \pm \sigma=22.8 \pm 2.6), 2-\mathrm{BLV}+(\mathrm{M} \pm \sigma=35.1 \pm 6.7), 3-\mathrm{BTub}+(\mathrm{M} \pm \sigma=27.0 \pm 4.2)$.

of control, BLV+, and BTub+ groups both by U criterion differences and the Splitter treatment. Whereas control groups in March and December did not differ in coordinates of the Shape Index BS_1 ( $\geq \geq 0.05)$, we united them, and compared with all BLV+ animals (Figure 8(b)). It was found that differences between these two united groups were highly significant. These results suggest that this serum index can be used as a reference for identification of BLV+ animals. Further studies are required. 


\subsection{Milk}

Milk is the most variable biological fluid because its content depends on age, hormonal state, season, and nutrition of animal. Milk, as well as serum, contains antibodies that appear in response to bacterial or viral infection at disease. We studied milk in a stall period, when cattle had quite uniform feed and conditions of detention in different farms. Figure 9 shows dried drops and the AMI curves of milk of different groups of animals under study. Reproducibility of drops' images was high. Milk spots in control group had mostly uniform homogeneous structure, when spots of some BLV+ animals, had randomly located holes on the surface, which formed during drying. These holes were due to decreased adhesion of protein aggregates to the glass surface, and led to discontinuities in the protein film under the action of deformation forces. Milk spots of BTub+ animals looked denser. They formed bizarre cracks after 2 - 3 days of drying, giving evidence of decreasing of viscoelastic properties of dried milk film. Drop drying processes of milk of different cattle groups are shown on video clips.

Control: https://www.dropbox.com/s/rjpciefl3x8dqpv/Milk_Control.mp4?dl=0

BLV+: https://www.dropbox.com/s/hsq7zls6qtyfmty/Milk_BLV\%2B.mp4?dl=0

BTub+: https://www.dropbox.com/s/gb1ev5wcep2m5ls/Milk_BTub\%2B.mp4?dl=0.

We can assume that milk of BTub+ animals adheres to the glass surface more strongly than in control group. Thus, mechanical properties of the milk samples in the groups under study were different, as well as shape features of their AMI curves (Figure 9). In the December series, the Shape Index BU_1 was the best for BLV+ animals recognition $(\mathrm{P} \leq 0.01)$, while the data of BTub+ animals did not differ from control $(\mathrm{P} \geq 0.05)$. The Shape Index BU_4 was highly significant for BTub+ animals recognition, and significant for identification of the BLV+ animals (Figure 10(a)). It is notable that BLV+ and BTub+ groups took place on opposite sides of the control on the plate of features of the Shape Index BU_4 (Figure 10(b)). Despite the fact that the data of March series had moved from the December data for both BU_1 and BU_4 Shape Indices, the last one still distinguished BLV+ and BTub+ groups. The united (December + March) data were also distinguished between control, BLV+ and BTub+ animals using BU_1 and BU_4 Shape Indexes respectively (Figure 10(c), Figure 10(d)). It gives hope to the possibility of diagnosis of these dangerous diseases using simple, rapid and noninvasive method.

Our study showed that using bottom-up process in sessile desiccated drops of biological fluids as a native physical phenomenon, it is possible to get quantitative information about health, and distinguish leukemia virus carriers from tuberculosis bacteria carriers.

It means that qualitative differences between fluids in these groups significantly exceed the total error of the method associated with such unstable object, like a drop. The mechanism of these differences is based on immune response of organism to viral or bacterial invasion, which accompanied by different biochemical consequences, changed fluids content [48]. These effects become apparent when the components of biological fluids
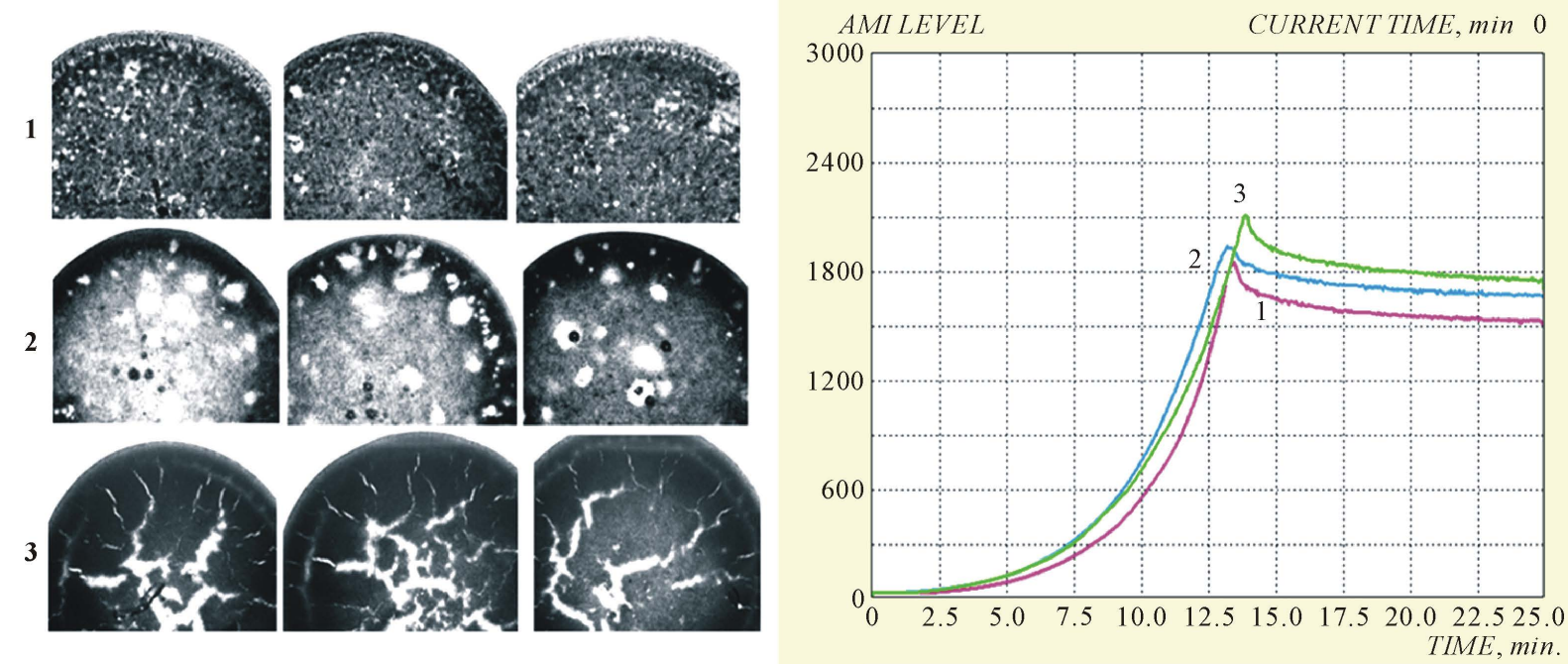

Figure 9. Dried milk drops images (left, three drops of each sample): 1-Control, 2-BLV+, 3-BTub+; (right, the AMI curves of the samples): $1-$ Control, $2-\mathrm{BLV}+, 3-\mathrm{BTub}+$. 


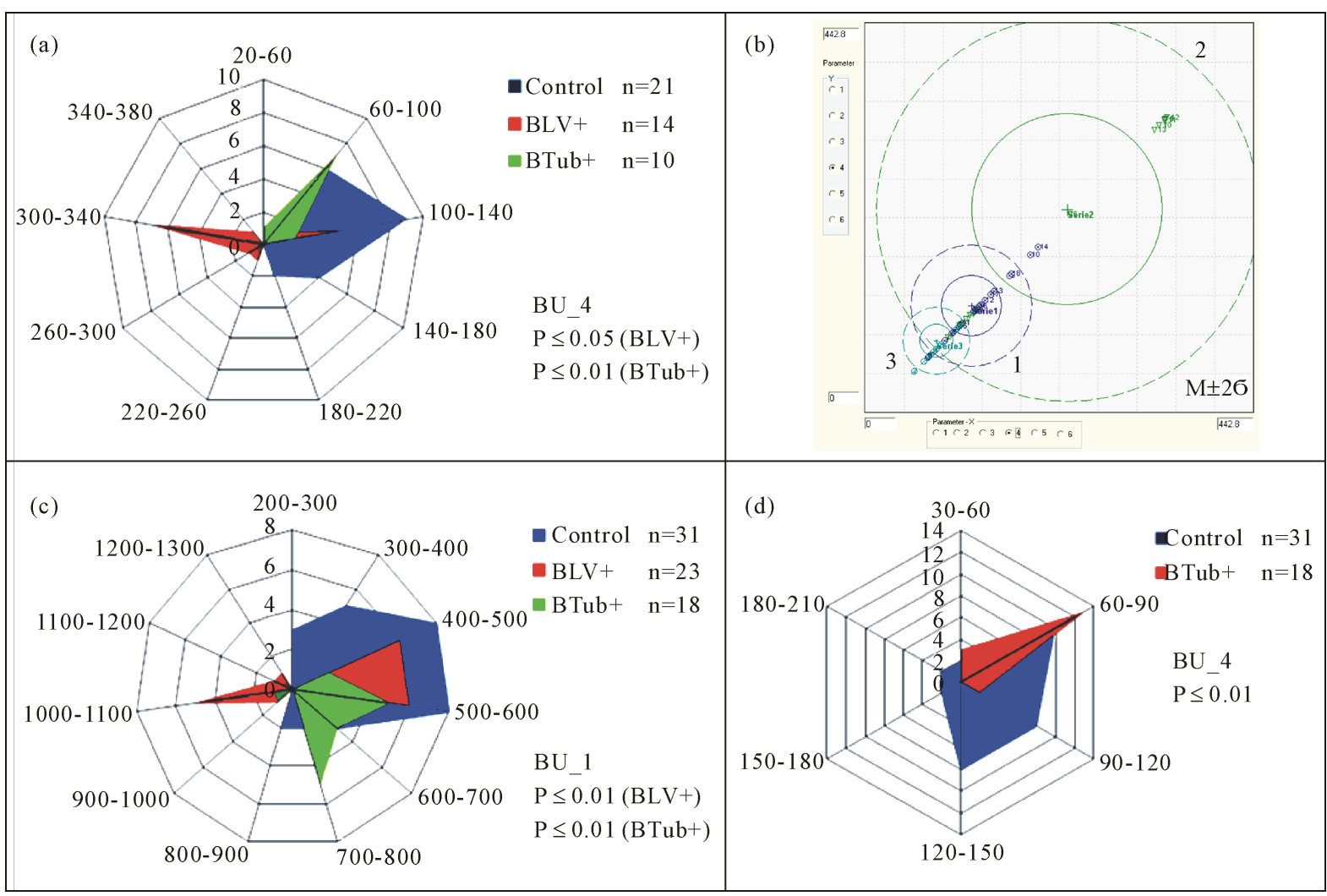

Figure 10. The Shape Indices BU_4 (a), (b), (d) and BU_1 (c) frequency data distribution of milk samples in control, BTub+ and BLV+ animals: (a) December data, (b) representation of the same data at the splitter interface: 1 -Control (M \pm $\sigma=121.2 \pm 37.1), 2-B L V+(M \pm \sigma=230.6 \pm 109.1), 3-B T u b+(M \pm \sigma=81.1 \pm 19.2)$; (c) united data (December + March) in control, BLV+ and BTub+ animals; (d) united data (December + March) in control and BTub+ animals.

(mostly proteins) form aggregates, sediment, and exert their adhesive and viscoelastic properties [49]. In accordance with DDT drop of tested fluid dried on a polished quartz plate, oscillated with constant frequency-60 $\mathrm{kHz}$. Mechanical properties of the drop changed during drying, and influenced the electrical conductivity of the quartz plate. This signal was converted to the Acoustical-Mechanical Impedance (AMI) and displayed as a curve in coordinates AMI vs. Time. Shape of the AMI curve reflected this dynamics, and was used as a target for quantitative comparison between control and infected animals. The joint histograms showed that a part of BLV+ and BTub+ samples usually fall into control group. It is known that the AGID is a specific, but not very sensitive test for detecting antibody in serum samples from individual animals. It is also unsuitable for milk samples (except first colostrums) because of lack of specificity and sensitivity [50]. It is known also that a coinfection with BLV and BTub in a Holstein cow is endemic in many cattle herds [51]. We tested not only serum, but blood and milk from BLV-infected animals, using AGID as a reference test, and got highly significant differences with control group. A large body of evidence now exists to support the high specificity of the single comparative intradermal skin test with typical specificity estimates being greater than $99.9 \%$. However, the sensitivity of the test remains moderate with estimates typically in the range 50\% - 60\% [50]. For checking up the real sensitivity and specificity of DDT test, it is necessary to control the results with blood cells analysis (for BLV+) and postmortem tissue analysis (for Btub+) in future. Also the most representative samples ( $\sim 100$ animals for every sample) would be desirable. Tests of artificial neural networks generally were successful. Such mediums as milk and blood gave reliable identification with the minimal complexity of neural network ( 1 - 2 neurons in a hidden layer) in cases of BLV+ (Table 2). BTub+ cases were quite similar to the previous ones. Meanwhile testing of serum both with BTub+ and BLV+ inclined to the system of significantly worse prognostic ability, which was compensated by increased neural network complexity (5 - 8 neurons in a hidden layer). This result may indicate further instability in a practical use. The task of sample preparation and/or further advance in signal preprocessing must be solved in order to approve the feasibility of neural network method. 
Table 2. Comparative structure of successful artificial neural network models.

\begin{tabular}{ccc}
\hline Object & Diagnosis & $\begin{array}{c}\text { Complexity } \\
\text { (Size of a Hidden Layer) }\end{array}$ \\
\hline Blood & BLV+ & 1 \\
Milk & BLV+ & 1 \\
Milk & BTub+ & 2 \\
Serum & BLV+ & 8 \\
Serum & BTub+ & 5 \\
\hline
\end{tabular}

\section{Conclusion and Outlook}

In this paper, we represented the DDT as one more way to obtain diagnostic information from complex liquids, using biological fluids of healthy and infected cattle, as an example. We did not use any chemicals or pretreatment procedures. Only a native phenomenon of self-organizing processes in sessile desiccated drops participated as a whole in this diagnostics. Dynamics of integral mechanical properties of the bottom adsorption layer, including mass, friction, adhesion and viscoelasticity, keenly reflected a cascade of phase transitions in drying drops due to water evaporation. The fact is that this dynamics was different in control, BVL-infected, and BTubinfected animals. Thus, we have received experimental validation that this technique deserves further development in the direction of veterinary diagnostics. Small-scale production of diagnostic devices should be established to carry out independent tests. By the consumer qualities, our method has advantages over existing methods. First, only one drop of fluid ( $3 \mu \mathrm{l})$, as it is, should be used (versus expensive chemicals and time-consuming procedures in usual techniques); second, the analysis takes $\sim 20$ min (versus some days in conventional methods), third, measuring procedure is very easy, and can be available for people without special education; forth, the device is space saver, not expensive, and can be exploited in field conditions. Moreover, such promising method for data treatment as neural networks is available. On the other hand, there are some problems that must be addressed further research. The first is, whether one database for each fluid to be a reference for the different seasons, or they should be season-depending? Can we find invariant features of diseases? If so, cloud reference database can be created and used via computers or smartphones. If not, every farm can create and use its own database. Let's listen to Nature.

\section{Acknowledgements}

We are grateful for the partial financial support from the Russian Foundation for Assistance to Small Innovative Enterprises in Science and Technology (Agreement No. 15/208/2012 from 28/09/2012), Investment and Venture Fund "Idea" of the Republic of Tatarstan (Contractual Agreement No. 10797p/19740 from 13/08/2012).

\section{References}

[1] Larson, R.G. (2014) Transport and Deposition Patterns in Drying Sessile Droplets. American Institute of Chemical Engineers Journal, 60, 1538-1571. http://dx.doi.org/10.1002/aic.14338

[2] Savina, L. (1999) Crystalline Structures of Serum of Healthy and Ill Patients. Soviet Kuban, Krasnodar, 96 p.

[3] Shabalin, V.N. and Shatokhina, S.N. (2001) Morphology of Biological Fluids. Khrisostom, Moscow, 304 p.

[4] Rapis, E. (2002) Changing the Physical Nonequilibrium Phase of Complex Plasma Proteins Film in Patients with Carcinoma. Techical Physics, 47, 510-512. http://dx.doi.org/10.1134/1.1470608

[5] Deegan, R.D. (2000) Pattern Formation in Drying Drops. Physical Review E, 61, 475-485. http://dx.doi.org/10.1103/PhysRevE.61.475

[6] Deegan, R.D., Bakajin, O., Dupont, T.F., Huber, G., Nagel, S.R. and Witten, T.A. (2000) Contact Line Deposits in an Evaporating Drop. Physical Review E, 62, 756-765. http://dx.doi.org/10.1103/PhysRevE.62.756

[7] Takhistov, P. and Chang, H.-C. (2002) Complex Stain Morphologies. Industrial and Engineering Chemistry Research, 41, 6256-6269. http://dx.doi.org/10.1021/ie010788+

[8] Shin, D.H., Lee, S.H., Jung, J.-Y. and Yoo, J.Y. (2009) Evaporating Characteristics of Sessile Droplet on Hydrophobic 
and Hydrophilic Surfaces. Microelectronic Engineering, 86, 1350-1353. http://dx.doi.org/10.1016/j.mee.2009.01.026

[9] Khellil, S. (2014) Patterns from Drying Drops. Advances in Colloid and Interface Science, 206, 372-381. http://dx.doi.org/10.1016/j.cis.2013.05.002

[10] Ramiasa, M., Ralston, J., Fetzer, R. and Sedev, R. (2014) The Influence of Topography on Dynamic Wetting. Advances in Colloid and Interface Science, 206, 275-293. http://dx.doi.org/10.1016/j.cis.2013.04.005

[11] Ristenpart, W.D., Kim, P.G., Domingues, C., Wan, J. and Stone, H.A. (2007) Influence of Substrate Conductivity on Circulation Reversal in Evaporating Drops. Physical Review Letters, 99, Article ID: 234502. http://dx.doi.org/10.1103/PhysRevLett.99.234502

[12] Darhuber, A.A. and Troian, S.M. (2005) Principles of Microfluidic Actuation by Modulation of Surface Stresses. Annual Review of Fluid Mechanics, 37, 425-455. http://dx.doi.org/10.1146/annurev.fluid.36.050802.122052

[13] Singha, S.K. and Dandapat, B.S. (2013) Spreading of a Non-Newtonian Liquid Drop over a Homogeneous Rough Surface. Colloids and Surfaces A, 419, 228-232. http://dx.doi.org/10.1016/j.colsurfa.2012.11.068

[14] Bhardwaj, R., Fang, X., Somasundaran, P. and Attinger, D. (2010) Self-Assembly of Colloidal Particles from Evaporating Droplets: Role of DLVO Interactions and Proposition of a Phase Diagram. Langmuir, 26, 7833-7842. http://dx.doi.org/10.1021/la9047227

[15] Okuzono, T., Kobayashi, M. and Doi, M. (2009) Final Shape of a Drying Thin Film. Physical Review E, 80, Article ID: 021603. http://dx.doi.org/10.1103/PhysRevE.80.021603

[16] Deegan, R.D., Bakajin, O., Dupont, T.F., Huber, G., Nagel, S.R. and Witten, T.A. (1997) Capillary Flow as the Cause of Ring Stains from Dried Liquid Drops. Nature, 389, 827-829. http://dx.doi.org/10.1038/39827

[17] Hu, H. and Larson, R.G. (2005) Analysis of the Effects of Marangoni Stresses on the Microflow in an Evaporating Sessile Droplet. Langmuir, 21, 3972-3980. http://dx.doi.org/10.1021/la0475270

[18] Tarasevich, Y.Y. (2005) Simple Analytical Model of Capillary Flow in an Evaporating Sessile Drop. Physical Review E, 71, Article ID: 027301. http://dx.doi.org/10.1103/PhysRevE.71.027301

[19] Yakhno, T.A., Kazakov, V.V., Sanin, A.G., Shaposhnikova, O.B. and Chernov, A.S. (2007) Mechanical Properties of Adsorption Layers in Solutions of Human Blood Serum Proteins: A Comparative Assessment. Technical Physics, 52, 510-514. http://dx.doi.org/10.1134/S1063784207040184

[20] Yakhno, T.A. and Yakhno, V.G. (2009) Structural Evolution of Drying Drops of Biological Fluid. Technical Physics, 54, 1219-1227. http://dx.doi.org/10.1134/S1063784209080210

[21] Yakhno, T. (2008) Salt-Induced Protein Phase Transitions in Drying Drops. Journal of Colloid and Interface Science, 318, 225-230. http://dx.doi.org/10.1016/j.jcis.2007.10.020

[22] Kuncicky, D.M. and Velev, O.D. (2008) Surface-Guided Templating of Particle Assemblies inside Drying Sessile Droplets. Langmuir, 24, 1371-1380. http://dx.doi.org/10.1021/la702129b

[23] Popov, Y. (2005) Evaporative Deposition Patterns: Spatial Dimensions of the Deposit. Physical Review E, 71, Article ID: 036313. http://dx.doi.org/10.1103/PhysRevE.71.036313

[24] Yakhno, T.A., Yakhno, V.G. and Sokolov, A.V. (2005) Shaping Processes in Drying Drops of Blood Serum in Norm and Pathology. Biophysics, 50, 638-645. http://www.maik.ru/contents/biophys/biophys4_5v50cont.pdf

[25] Kim, N., Li, Z., Hurth, C., Zenhausern, F., Chang, S.F. and Attinger, D. (2012) Identification of Fluid and Substrate Chemistry Based on Automatic Pattern Recognition of Stains. Analytical Methods, 4, 50-57. http://dx.doi.org/10.1039/c1ay05338h

[26] Brutin, D., Sobac, B., Loquet, B. and Sampol, J. (2011) Pattern Formation in Drying Drops of Blood. Journal of Fluid Mechanics, 667, 85-95. http://dx.doi.org/10.1017/S0022112010005070

[27] Killeen, A.A., Ossina, N., McGlennen, R.C., Minnerath, S., Borgos, J., Alexandrov, V. and Sarvazyan, A. (2006) Protein Self-Organization Patterns in Dried Serum Reveal Changes in B-Cell Disorders. Molecular Diagnosis \& Therapy, 10, 371-380. http://dx.doi.org/10.1007/BF03256214

[28] Yakhno, T.A., Yakhno, V.G., Sanin, A.G. and Shmelev, I.I. (2002) Study of the Dynamics of Phase Transitions in Liquids of Different Types by Measuring the Acoustomechanical Impedance of a Drying Drop. Biophysics, 47, 10211025. http://www.maik.ru/abstract/biophys/2/biophys1021_abstract.pdf

[29] Ravera, F., Ferrari, M., Santini, E. and Liggieri, L. (2005) Influence of Surface Processes on the Dilational Visco-Elasticity of Surfactant Solutions. Advances in Colloid and Interface Science, 117, 75-100. http://dx.doi.org/10.1016/j.cis.2005.06.002

[30] Kastantin, M., Langdon, B.B. and Schwartz, D.K. (2014) A Bottom-Up Approach to Understanding Protein Layer Formation at Solid-Liquid Interfaces. Advances in Colloid and Interface Science, 207, 240-252. http://dx.doi.org/10.1016/j.cis.2013.12.006

[31] Vashist, S.K. and Vashist, P. (2011) Recent Advances in Quartz Crystal Microbalance-Based Sensors. Journal of Sen- 
sors, 2011, Article ID: 571405. http://dx.doi.org/10.1155/2011/571405

[32] Voinova, M.V. (2009) On Mass Loading and Dissipation Measured with Acoustic Wave Sensors: A Review. Journal of Sensors, 2009, Article ID: 943125, 13 p. http://dx.doi.org/10.1155/2009/943125

[33] Biancoa, M., Aloisia, A., Arimaa, V., Capello, M., Ferri-Borgogno, S., Novelli, F., Leporatti, S. and Rinaldi, R. (2013) Quartz Crystal Microbalance with Dissipation (QCM-D) as Tool to Exploit Antigen-Antibody Interactions in Pancreatic Ductal Adenocarcinoma Detection. Biosensors and Bioelectronics, 42, 646-652. http://dx.doi.org/10.1016/j.bios.2012.10.012

[34] Lin, T.Y., Hu, C.H. and Chou, T.C. (2004) Determination of Albumin Concentration by MIP-QCM Sensor. Biosensors and Bioelectronics, 20, 75-81. http://dx.doi.org/10.1016/j.bios.2004.01.028

[35] Yakovleva, M.E., Safina, G.R. and Danielsson, B. (2010) A Study of Glycoprotein-Lectin Interactions Using Quartz Crystal Microbalance. Analytica Chimica Acta, 668, 80-85. http://dx.doi.org/10.1016/j.aca.2009.12.004

[36] Kurosawa, S., Nakamura, M., Park, J.W., Aizawa, H., Yamada, K. and Hirata, M. (2004) Evaluation of a High-Affinity QCM Immunosensor Using Antibody Fragmentation and 2-Methacryloyloxyethyl Phosphorylcholine (MPC) Polymer. Biosensors and Bioelectronics, 20, 1134-1139. http://dx.doi.org/10.1016/j.bios.2004.05.016

[37] Spinella, K., Mosiello, L., Palleschi, G. and Vitali, F. (2013) Development of a QCM (Quartz Crystal Microbalance) Biosensor to the Detection of Aflatoxin B1. Open Journal of Applied Biosensor, 2, 112-119. http://dx.doi.org/10.4236/ojab.2013.24015

[38] Pashley, R.M. and Kitchener, J.A. (1979) Surface Forces in Adsorbed Multilayers of Water on Quartz. Journal of Colloid and Interface Science, 71, 491-500. http://dx.doi.org/10.1016/0021-9797(79)90323-0

[39] Yakhno, T.A., Kazakov, V.V., Sanin, A.G., Shaposhnikova, O.B. and Chernov, A.S. (2007) Dynamics of Phase Transitions in Drying Drops of Human Serum Protein Solutions. Technical Physics, 52, 515-520. http://dx.doi.org/10.1134/S1063784207040196

[40] Yakhno, T.A., Yakhno, V.G., Sanin, A.G., Sanina, O.A. and Pelyushenko, A.S. (2004) Protein and Salt: Spatiotemporal Dynamics of Events in a Drying Drop. Technical Physics, 49, 1055-1063. http://dx.doi.org/10.1134/1.1787668

[41] Yakhno, T., Sanin, A., Pelyushenko, A., Kazakov, V., Shaposhnikova, O., Chernov, A., Yakhno, V., Vacca, C., Falcone, F. and Johnson, B. (2007) Uncoated Quartz Resonator as a Universal Biosensor. Biosensors and Bioelectronics, 22, 21272131. http://dx.doi.org/10.1016/j.bios.2006.09.029

[42] Yakhno, T.A., Sanin, A.G., Vacca, C.V., Falcione, F., Sanina, O.A., Kazakov, V.V. and Yakhno, V.G. (2009) A New Technology for Studying Multicomponent Liquids Using a Quartz Crystal Resonator: Theory and Applications. Technical Physics, 54, 1423-1430. http://dx.doi.org/10.1134/S1063784209100041

[43] Yakhno, T., Sanin, A., Kazakov, V., Sanina, O., Vacca, C., Falcione, F. and Yakhno, V. (2010) Uncoated Quartz Resonator as a Universal Biosensor. In: Somerset, V.S., Ed., Intelligent and Biosensors, INTECH, 345-362. http://www.sciyo.com/articles/show/title/uncoated-quartz-resonator-as-a-universal-biosensor

[44] Yakhno, T., Sanin, A., Yakhno, V., Pelyushenko, A., Egorova, N.A., Terentiev, I.G., Smetanina, S.V., Korochkina, O.V. and Yashukova, E.V. (2005) The Informative-Capacity Phenomenon of Drying Drops. Aptitude Test in Medical Diagnostics. IEEE Engineering in Medicine and Biology Magazine, 24, 96-104. http://dx.doi.org/10.1109/MEMB.2005.1411354

[45] Miller, J.M., Schmerr, M.J. and Van Der Maaten, M.J. (1981) Comparison of Four Serologic Tests for the Detection of Antibodies to Bovine Leukemia Virus. American Journal of Veterinary Research, 42, 5-8. http://www.ncbi.nlm.nih.gov/pubmed/6261620

[46] Strain, S.A.J., McNair, J. and McDowell, S.W.J. (2011) Bovine Tuberculosis: A Review of Diagnostic Tests for M. bovis Infection in Badgers. Bacteriology Branch Veterinary Sciences Division Agri-Food and Biosciences Institute, $45 \mathrm{p}$. http://www.bovinetb.info/docs/bovine-tuberculosis-a-review-of-diagnostic-tests-for-m-bovis-infection-in-badgers.pdf

[47] Sprent, P. and Smeeton, N.C. (2001) Applied Nonparametric Statistical Methods. 3rd Edition, Chapman \& Hall/CRC, Boca Raton, London, New York, Washington DC, CRC Press LLC, 463 p. http://biblioteca.cunef.edu/gestion/catalogo/doc_num.php?explnum_id=519

[48] Yakhno, T. (2010) Protein Phase Instability Developed in Plasma of Sick Patients: Clinical Observations and Model Experiments. Natural Science, 2, 220-227. http://dx.doi.org/10.4236/ns.2010.23034

[49] Yakhno, T. (2011) Blood as a Polydisperse System. Lambert Academic Publishing GmbH \& Co, Germany, 313 p. (In Russian) www.lap-publishing.com/catalog/details/store/cn/book/978-3-8443-5767-7/Кровь-как-полидисперсная-система?sear ch=Older\%20Miao\%20People\%20and\%20Rural\%20Health\%20Policy\%20in\%20China

[50] OIE Terrestrial Manual (2012) Enzootic Bovine Leucosis. 1-11. http://www.oie.int/fileadmin/Home/fr/Health_standards/tahm/2.04.11_EBL.pdf 
[51] Fitzgerald, S.D., Sledge, D.G., Maes, R., Wise, A. and Kiupel, M. (2009) Coinfection of a Cow with Bovine Leukemia Virus and Mycobacterium bovis. Journal of Veterinary Diagnostic Investigation, 21, 878-882.

http://dx.doi.org/10.1177/104063870902100621

\section{Nomenclature}

AMI-Acoustical-Mechanical Impedance

BLV+_-Bovine Leukemia Virus Seropositive Animals

BTub+-Bovine PPD-Tuberculin Seropositive Animals

DDT_-Drying Drop Technology

ESR-Erythrocyte Sedimentation Rate

SI-Shape Index

PCV_-Packed Cell Volume 


\section{Appendix A. Description of the Base Simple (BS) Shape Indices}

Figure A1 shows a typical shape of the AMI curve. X-axis is time t, Y-axis is measured values of the AMI modulus A(t). Figure A1 shows two indicated characteristic values of the curve. They are: point of the maximum of abscissa tM and ordinate $\mathbf{A}(\mathbf{t M})$ and the steady-state-level SSL. Hereafter the values $\mathbf{A}(\mathbf{t M})$ and SSL are used to calculate the shape indices.

All the parameters included in the calculated shape indices 1, 3, 6 are determined by the geometry of the curve sections near the maximum.

Figure A2 shows the position of point 1 with following properties. This point is located on the horizontal line with level SSL $\times \mathbf{1 . 0 2}$ and intersecting with ascending part of the curve (on the left of the $\mathbf{t M}$ ). The distance $\mathbf{s}$ between abscissa of the point $\mathbf{1}$ and $\mathbf{t M}$ is using as its own new scale of the curve.

Figure A3 shows the positions of points 2, 3, 4 that are found using the following operations. Point 2 is located on the horizontal line having level SSL $\times \mathbf{1 . 0 2}$ and intersecting with descending part of the curve (on the right of the $\mathbf{t M}$ ). Point $\mathbf{3}$ is located on the ascending part of the curve and has abscissa (tM - 2s). Point $\mathbf{4}$ is located on the descending part of the curve (on the right of the $\mathbf{t M}$ ) and has abscissa $(\mathbf{t} \mathbf{M}+\mathbf{s})$.

Figure A4 shows the position of curvilinear trapezium that is marked with gray. Location of the vertices of this trapezium is clear from the picture. S2 is area of this curvilinear trapezium.

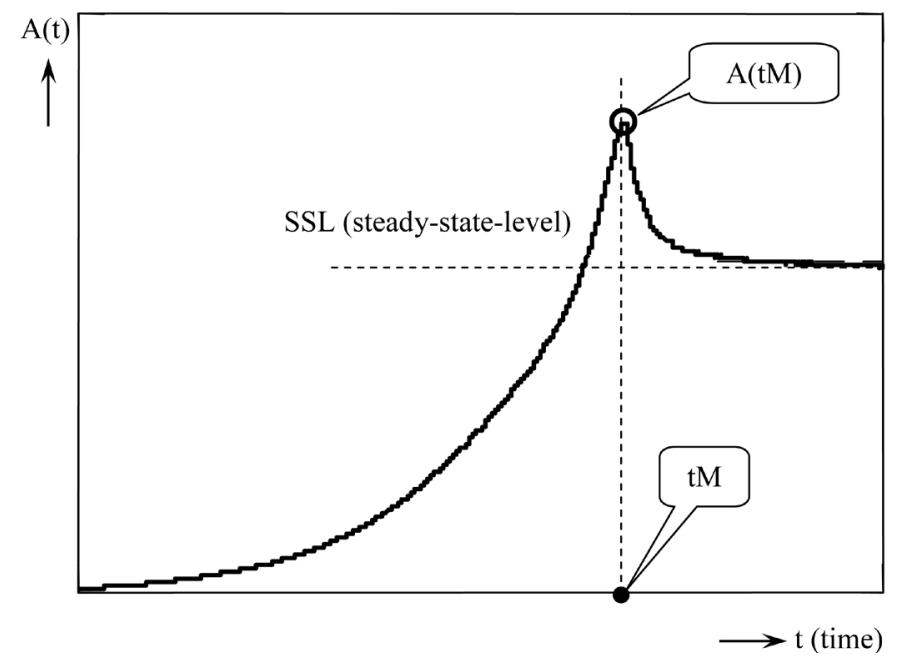

Figure A1. Typical shape of the recorded curve with indicated values of maximum and steady-state-level.

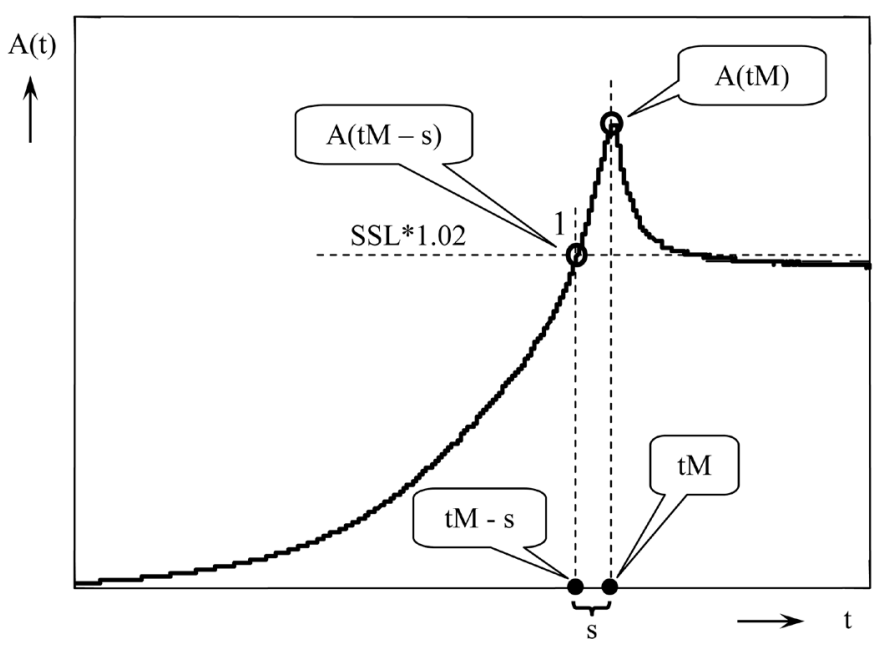

Figure A2. Location of point 1 and determination of the distance s. 


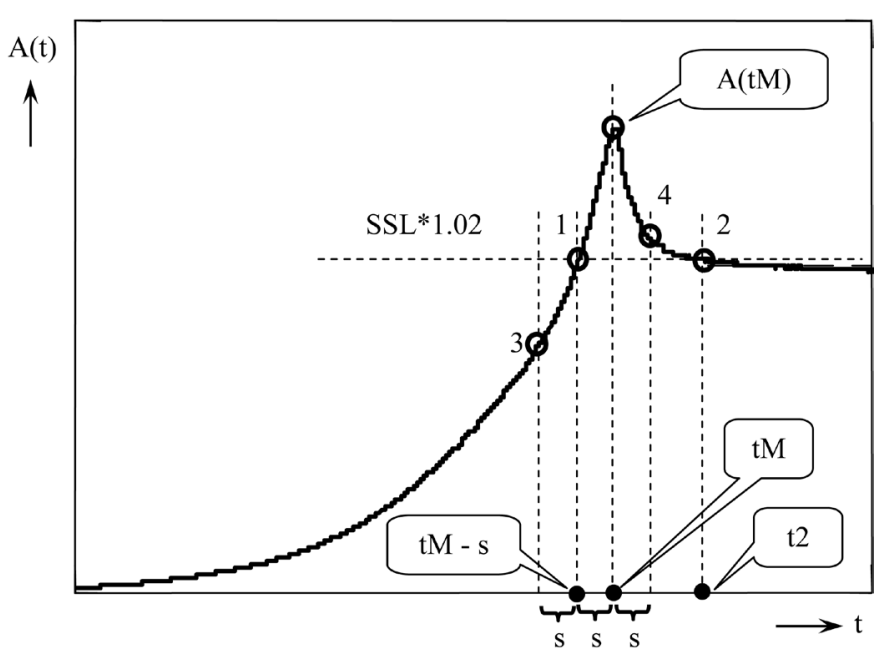

Figure A3. Location of points 2, 3, 4.

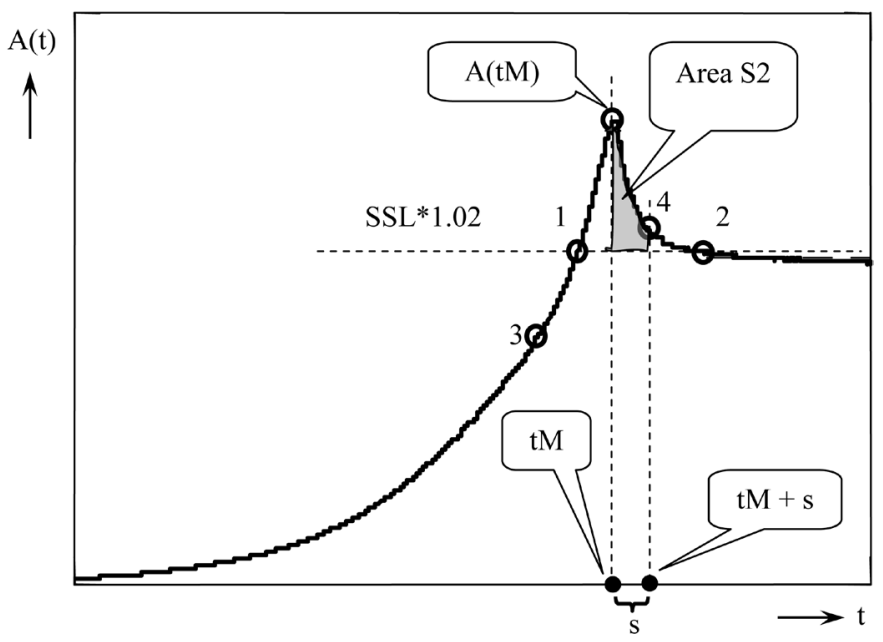

Figure 4. Position of curvilinear trapezium and determination of its area S2.

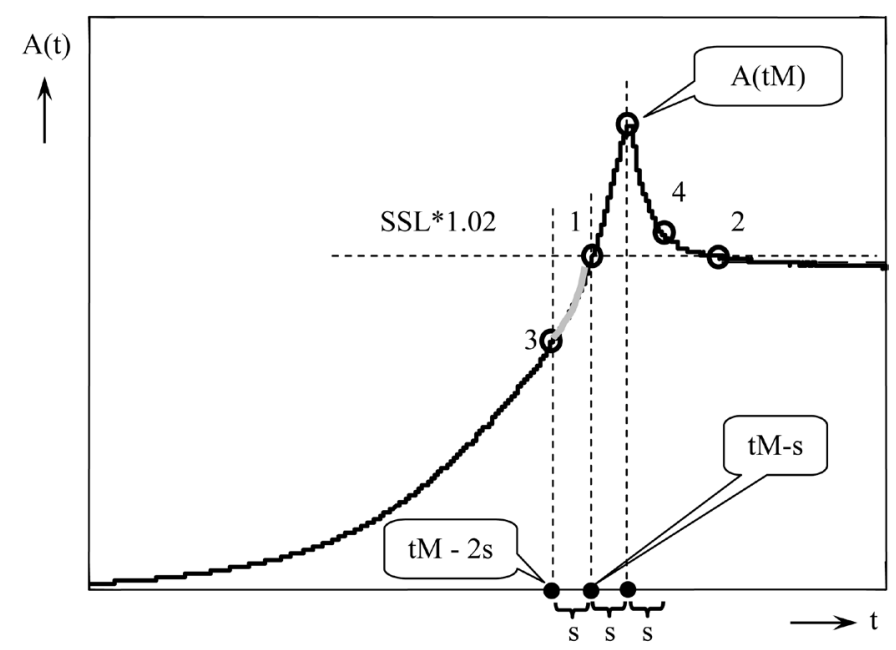

Figure A5. Calculating of the Shape index BS_1. 


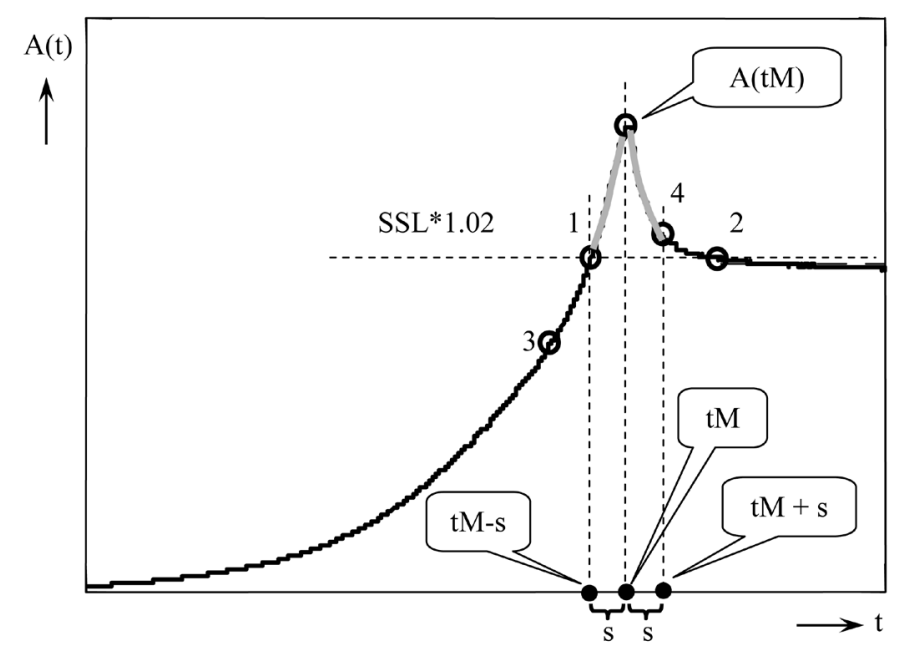

Figure A6. Calculating of the Shape index BS_3.

The calculated shape indices BS_1 and BS_3 include some combinations of the values were described above. Shape index BS_1 is average derivation of the part of the curve at the interval between points 3 and 1 (marked with gray at Figure A5).

$$
\text { Shape index } 1=\frac{1}{\mathrm{~s}} \cdot \sum_{\mathrm{tM}-2 \mathrm{~s}}^{\mathrm{tM}-\mathrm{s}} \frac{\mathrm{dA}(\mathrm{t})}{\mathrm{dt}}
$$

Shape index BS_3 is a difference of the average derivations at the ascending and descending parts of the curve at the interval between points 1 and 4 (marked with gray at Figure A6).

$$
\text { Shape index } 3=\frac{1}{\mathrm{~s}} \cdot \sum_{\mathrm{tM}-\mathrm{s}}^{\mathrm{tM}} \frac{\mathrm{dA}(\mathrm{t})}{\mathrm{dt}}-\frac{1}{\mathrm{~s}} \cdot \sum_{\mathrm{tM}}^{\mathrm{tM}+\mathrm{s}} \frac{\mathrm{dA}(\mathrm{t})}{\mathrm{dt}}
$$




\section{Appendix B. Description of the Base Universal (BU) Shape Indices}

Figure B1 shows the typical shape of the curve. The vertical line is the measured values of the AMI modulus Mod and the horizontal line is time.

Figure B2 shows the same curve with indicated value of the AMI steady state level and a point of the maximum AMI(tmax) (marked with $\square$ ) and its time tmax.

Figure B3 shows a curve of measuring current $\mathrm{u}(\mathrm{t})$, corresponding with the AMI curve of Figure B1. Constant value Uo is determined by the device parameters.

The variable $\mathrm{v}(\mathrm{t})=[\mathrm{Uo}-\mathrm{u}(\mathrm{t})]^{2}$ is introduced.

A typical shape of the curve $\mathbf{v}(\mathbf{t})$ and its steady state level is shown in Figure B4.

A new variable $\mathrm{UM}(\mathrm{t})$ is introduced.

$$
\mathrm{UM}(\mathrm{t})=\mathrm{AMI}(\mathrm{t})-\frac{\text { AMI steady state level }}{\mathrm{v} \text { steady state level }} \cdot \mathrm{v}(\mathrm{t})
$$

A typical shape of the curve $U M(t)$ is shown in Figure B5. The curve UM(t) has two extremums: UM(tmin) and UM(tmax), which are shown in Figure B5. It is easily to see that the time of maximum UM(t) is the same with tmax of maximum AMI(t) in Figure B2.

Three specific levels of variable UM(t) are introduced, as it is shown in Figure B6.

Level "reject +" (thin dashed line in Figure B6) lies on the horizontal beginning part of the UM(t). Level "reject + " is situated above time axis.

Level "reject -" (dot line in Figure B6) is situated below time axis at the distance equal "reject +". Level "UM(tmax)/3" (thick dashed line in Figure B6) is situated above time axis at the height a third of maximum value of $\mathrm{UM}(\mathrm{t})$.

Intersections of horizontal lines of described levels with curve UM(t) give four specific points, as it is shown in Figure B7.

So there are 6 points on the curve $U M(t)$. Their time coordinates are $t 1$, tmin, $t 2$, tmax, $t 3, t 4$.

Figure B8 shows the corresponding 6 points on a typical the AMI curve.

Area AS4 is introduced, as it is shown in Figure B9. AS4 is marked with grey.

Area SP2 is introduced, as it is shown in Figure B10. SP2 is marked with grey.

Total derivation TD is calculated on the time interval between tmax and t3. This part of the curve is marked as heavy gray line in Figure B11.

$$
\mathrm{TD}=\left|\sum_{\mathrm{tmax}}^{\mathrm{t} 3} \frac{\mathrm{d}[\mathrm{UM}(\mathrm{t})]}{\mathrm{dt}}\right|
$$



Figure B1. Typical shape of the AMI curve. 


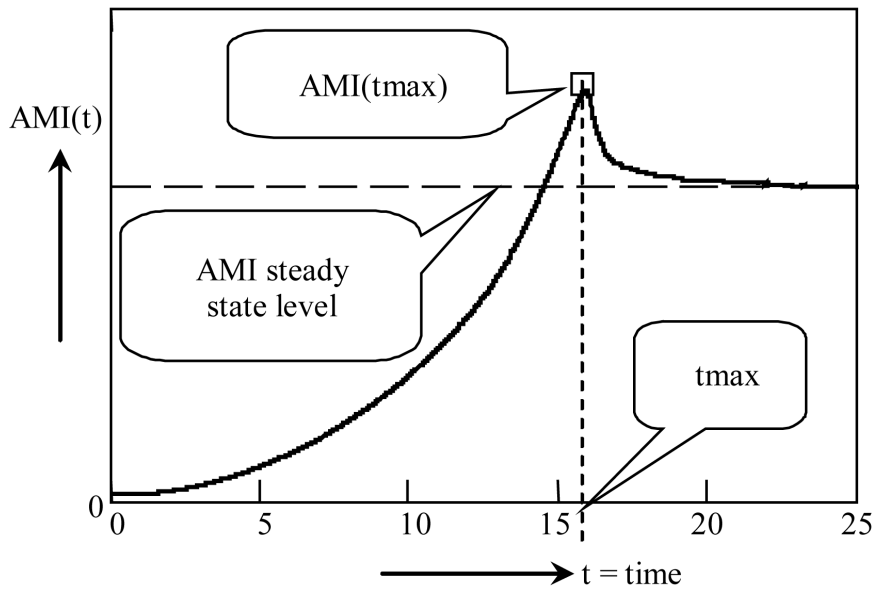

Figure B2. The AMI curve with indicated point of maximum and the AMI steady state level.

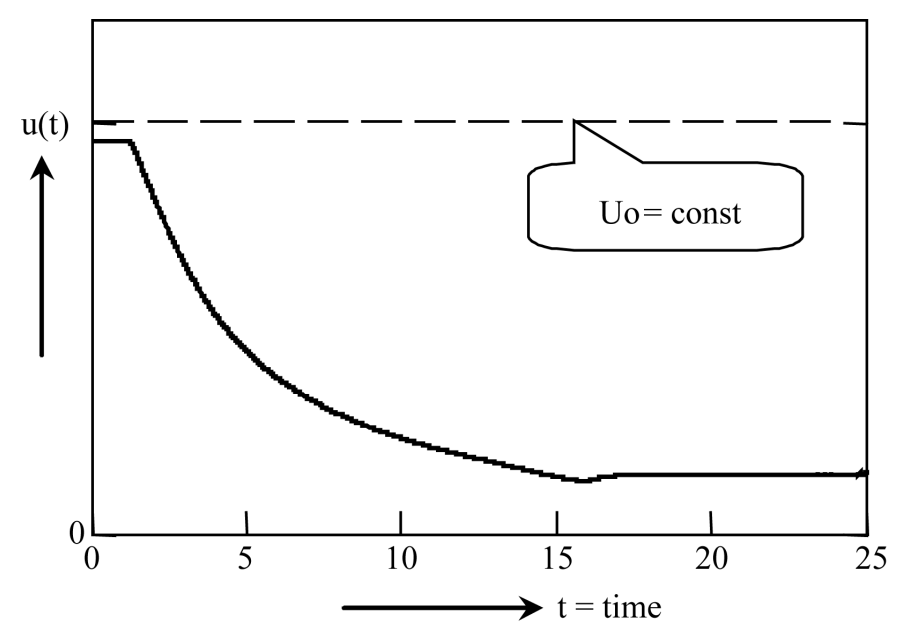

Figure B3. Registering current value, corresponding to the AMI curve of Figure B1.



Figure B4. Typical shape of the curve $\mathbf{v}(\mathbf{t})$ and its steady state level. 




Figure B5. Typical shape of the UM(t) curve and its extremums.



Figure B6. Three specific levels of variable UM(t).



Figure B7. Points of intersections of levels lines with curve UM(t). 


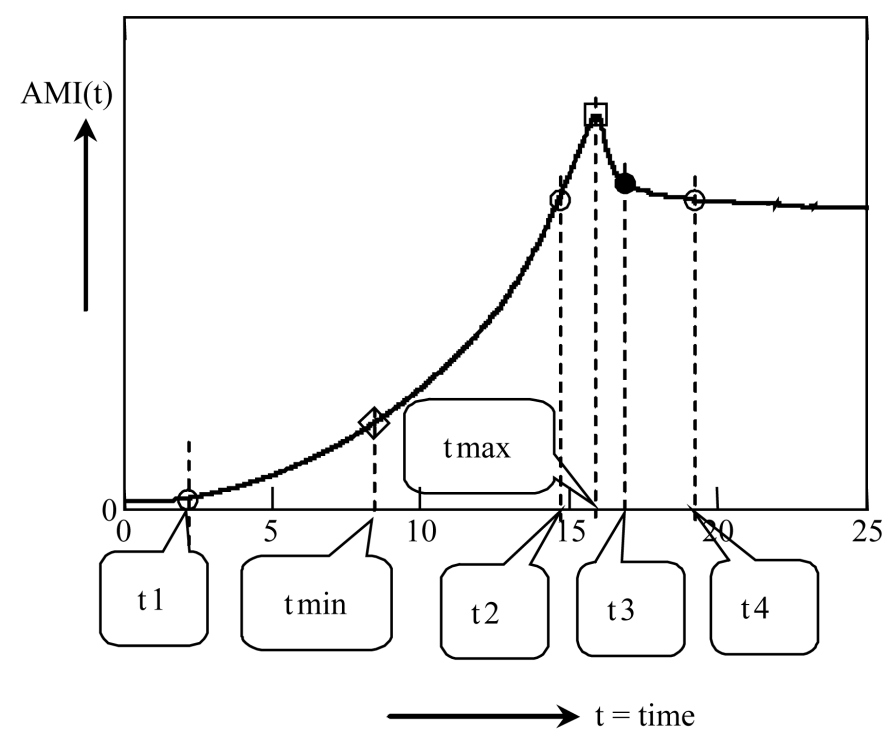

Figure B8. Described 6 points on a typical the AMI curve.

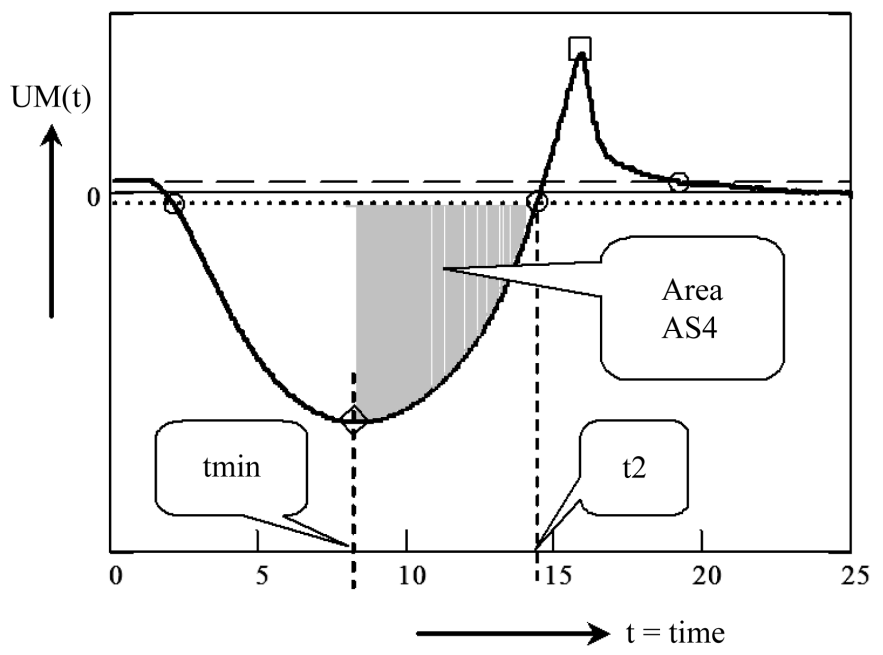

Figure B9. Area AS4 (marked with grey).

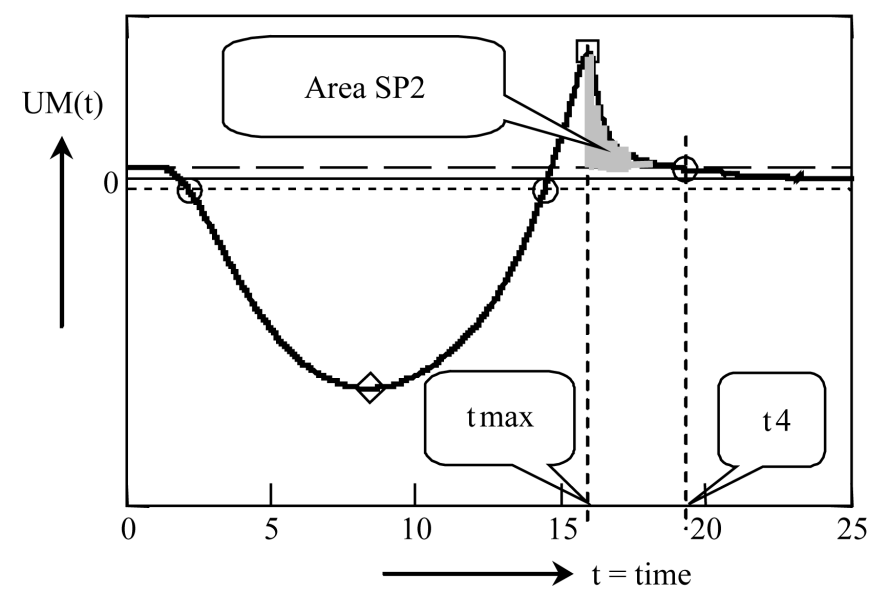

Figure B10. Area SP2 (marked with grey). 


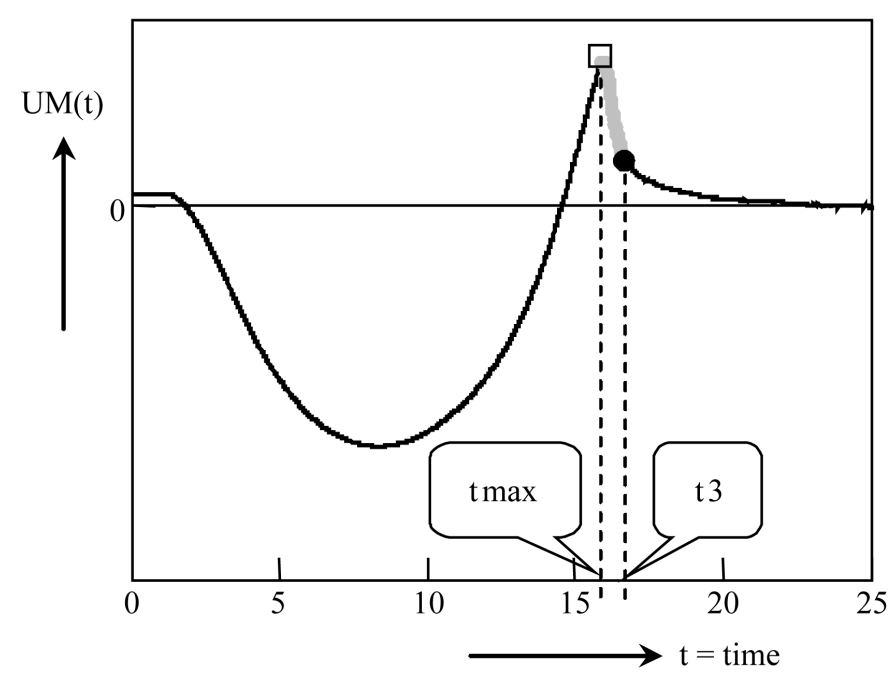

Figure B11. A part of the curve on which total derivation TD is calculated (marked as heavy gray line).

Calculating Shape Indexes

$$
\begin{aligned}
& \text { BU_1 }=\frac{\text { AMI }(\text { tmax })}{\text { AMI steady state level }}-1 \\
& \text { BU_2 }=\frac{\mathrm{SP} 2 \cdot(\mathrm{tmax}-\mathrm{t} 1)}{\mathrm{UM}(\mathrm{tmax}) \cdot(\mathrm{t} 4-\mathrm{tmax})} \\
& \text { BU_3 }=\mathrm{TD} \\
& \text { BU_4 }=\frac{\mathrm{UM}(\mathrm{tmin})}{\mathrm{UM}(\operatorname{tmax})} \\
& \text { BU_5 }=\frac{\mathrm{SP} 2}{\mathrm{t} 4-\mathrm{tmax}} \\
& \text { BU_6 }=\frac{\text { AS4 }}{\mathrm{t} 2-\mathrm{tmin}} \cdot(\mathrm{tmax}-\mathrm{tmin})
\end{aligned}
$$


Scientific Research Publishing (SCIRP) is one of the largest Open Access journal publishers. It is currently publishing more than 200 open access, online, peer-reviewed journals covering a wide range of academic disciplines. SCIRP serves the worldwide academic communities and contributes to the progress and application of science with its publication.

Other selected journals from SCIRP are listed as below. Submit your manuscript to us via either submit@scirp.org or Online Submission Portal.
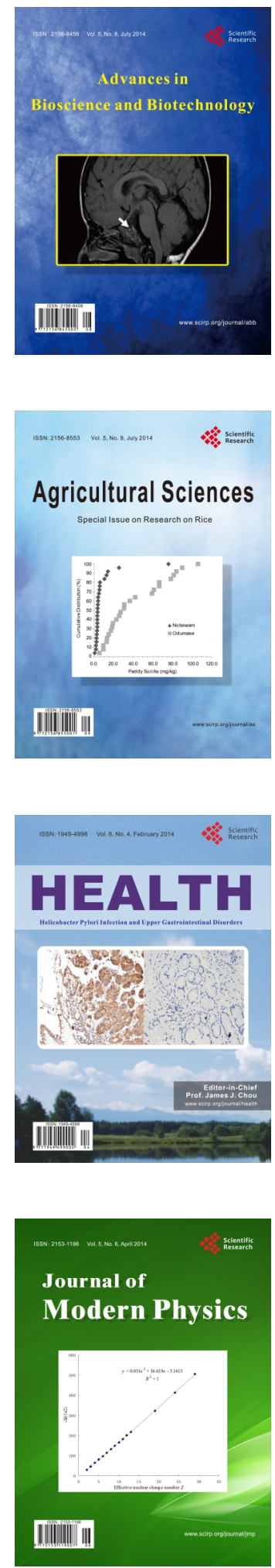
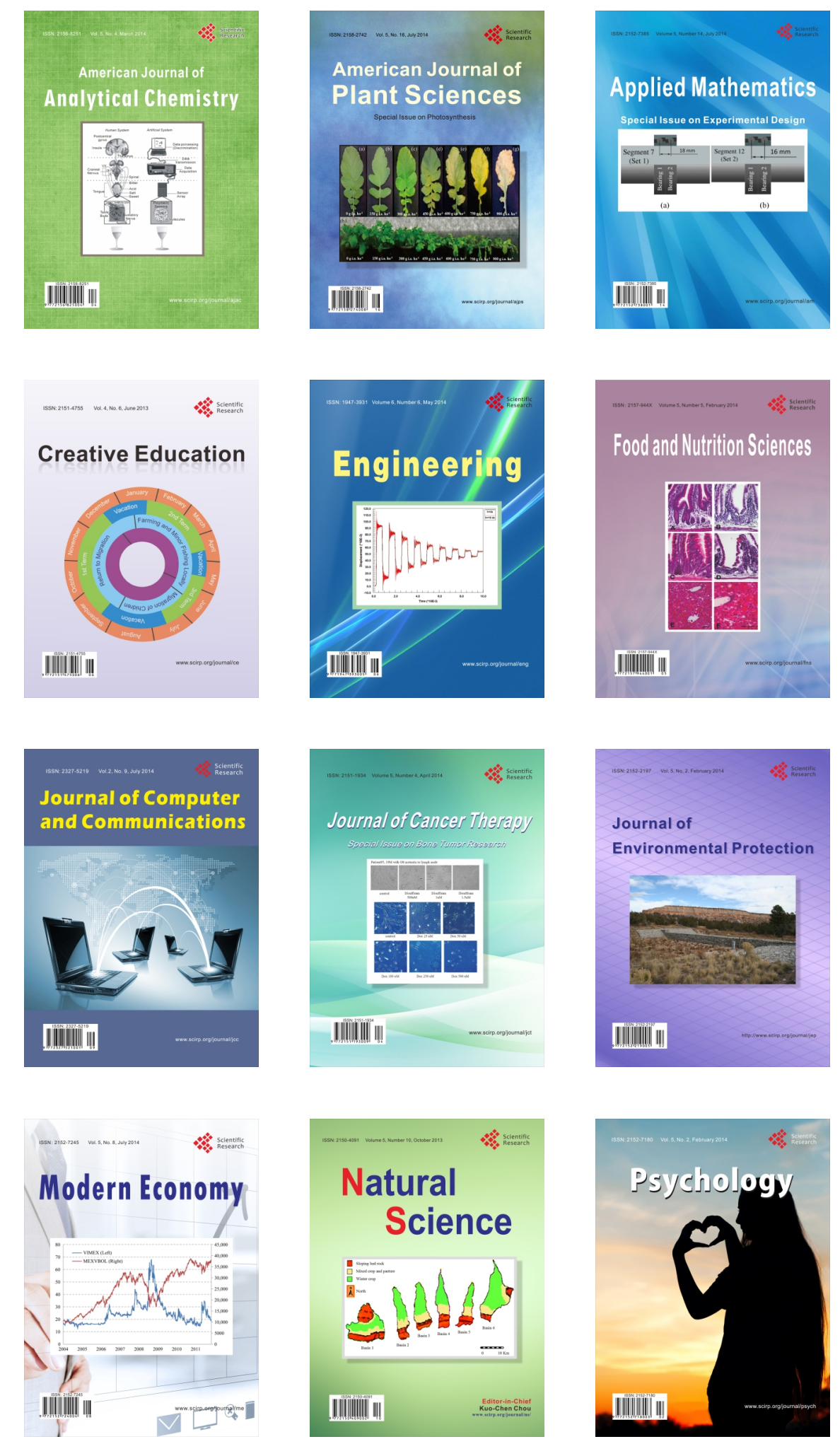